\title{
Report on FY18 Testing Results in Support of Integrated EPP-SMT Design Methods Development
}

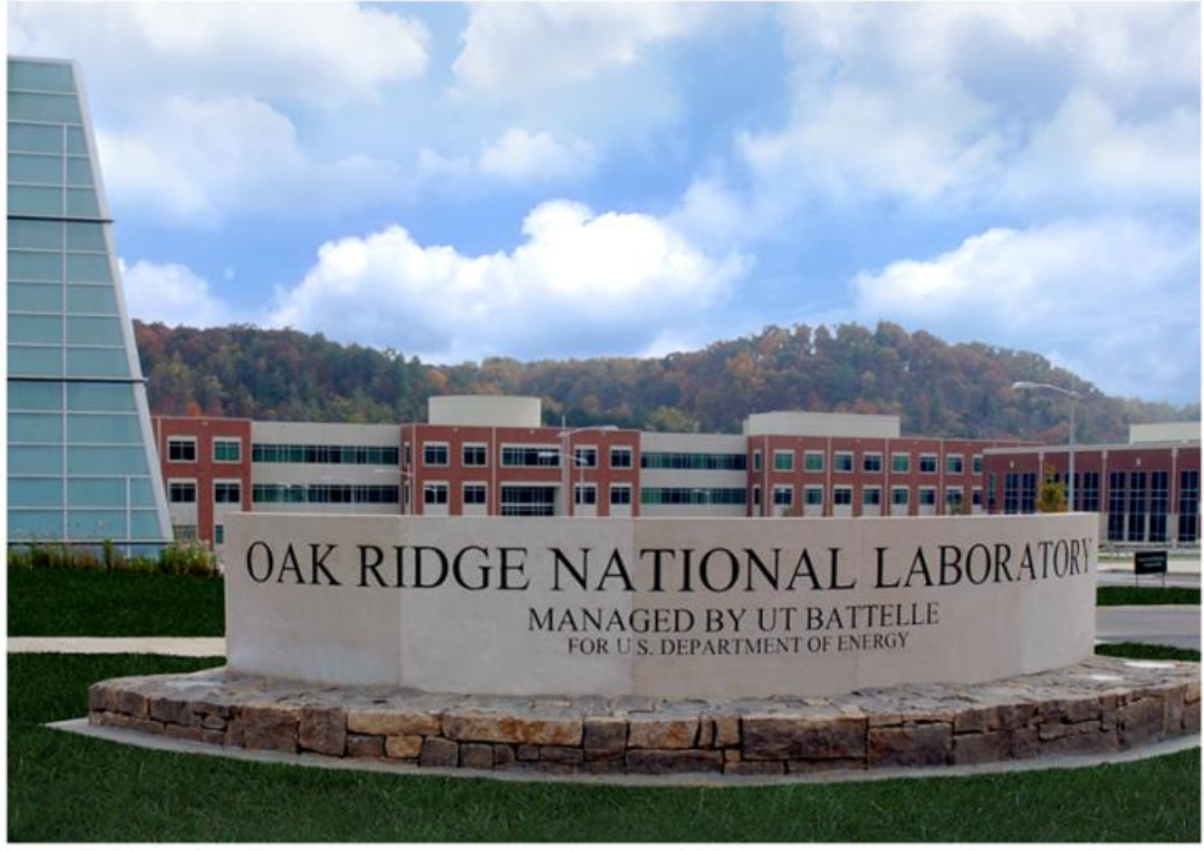

Approved for public release. Distribution is unlimited.

Yanli Wang

Robert I. Jetter Mark C. Messner

T.-L. Sham

August 3, 2018 


\title{
DOCUMENT AVAILABILITY
}

Reports produced after January 1, 1996, are generally available free via US Department of Energy (DOE) SciTech Connect.

Website http://www.osti.gov/scitech/

Reports produced before January 1, 1996, may be purchased by members of the public from the following source:

\author{
National Technical Information Service \\ 5285 Port Royal Road \\ Springfield, VA 22161 \\ Telephone 703-605-6000 (1-800-553-6847) \\ TDD 703-487-4639 \\ Fax 703-605-6900 \\ E-mail info@ntis.gov \\ Website http://www.ntis.gov/help/ordermethods.aspx
}

Reports are available to DOE employees, DOE contractors, Energy Technology Data Exchange representatives, and International Nuclear Information System representatives from the following source:

Office of Scientific and Technical Information

PO Box 62

Oak Ridge, TN 37831

Telephone 865-576-8401

Fax 865-576-5728

E-mail reports@osti.gov

Website http://www.osti.gov/contact.html

This report was prepared as an account of work sponsored by an agency of the United States Government. Neither the United States Government nor any agency thereof, nor any of their employees, makes any warranty, express or implied, or assumes any legal liability or responsibility for the accuracy, completeness, or usefulness of any information, apparatus, product, or process disclosed, or represents that its use would not infringe privately owned rights. Reference herein to any specific commercial product, process, or service by trade name, trademark, manufacturer, or otherwise, does not necessarily constitute or imply its endorsement, recommendation, or favoring by the United States Government or any agency thereof. The views and opinions of authors expressed herein do not necessarily state or reflect those of the United States Government or any agency thereof. 
Materials Science and Technology Division

\title{
REPORT ON FY18 TESTING IN SUPPORT OF INTEGRATED EPP-SMT DESIGN METHODS DEVELOPMENT
}

\author{
Yanli Wang, Robert I. Jetter*, Mark C. Messner† and T.-L. Sham† \\ * RI Jetter Consulting \\ $\uparrow$ Argonne National Laboratory
}

Date Published: August 3, 2018

Prepared by

OAK RIDGE NATIONAL LABORATORY

Oak Ridge, TN 37831-6283

managed by

UT-BATTELLE, LLC

for the

US DEPARTMENT OF ENERGY

under contract DE-AC05-00OR22725 



\section{CONTENTS}

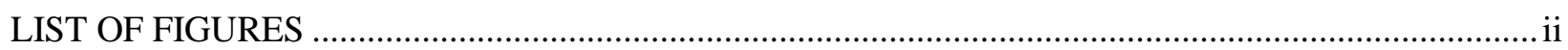

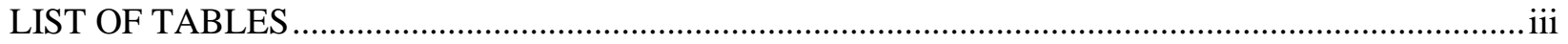

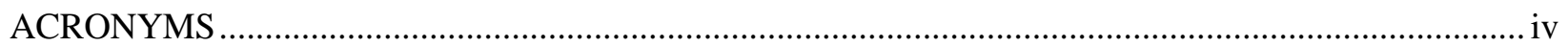

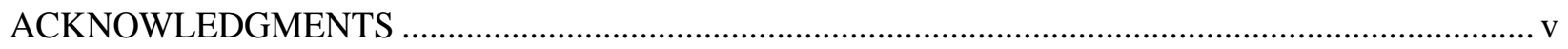

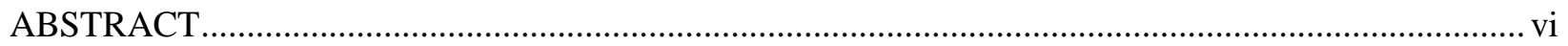

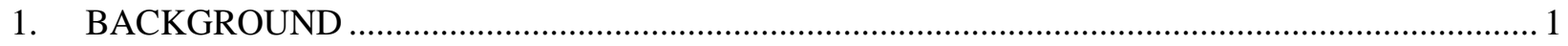

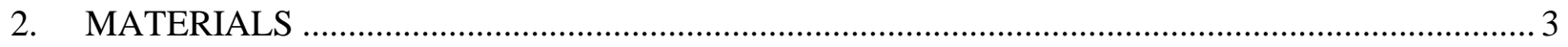

3. DEVELOPMENT OF SMT TEST METHODOLOGY …................................................... 3

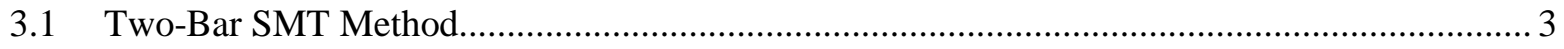

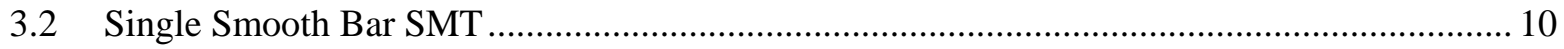

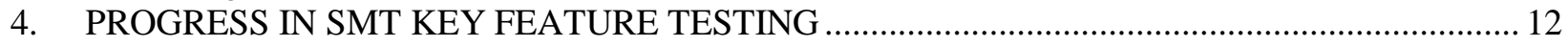

4.1 SMT Pressurization Testing on Alloy 617 at Low Strain Range .......................................... 12

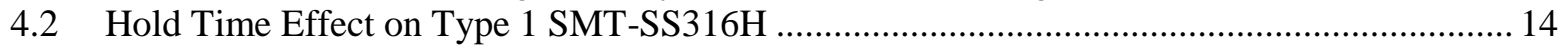

5. EXTENDED TESTING CAPABILITIES WITH KEY FEATURE ARTICLES FOR

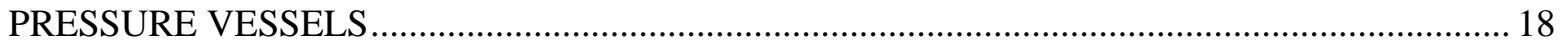

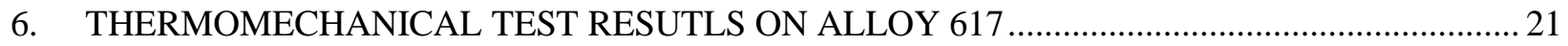

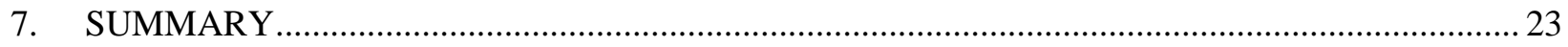

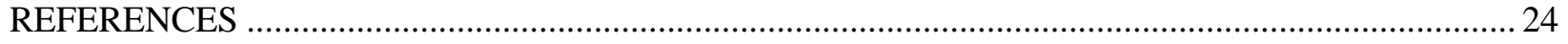




\section{LIST OF FIGURES}

Fig. 1. Schematics of the SMT specimen and two-bar SMT representation ............................................. 4

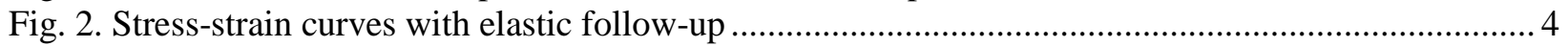

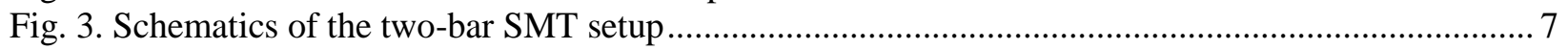

Fig. 4. Geometry of the standard creep fatigue specimen. Units are in $\mathrm{mm}$. ......................................... 7

Fig. 5. Applied end-displacement profile for one cycle of SMT creep-fatigue testing with tension

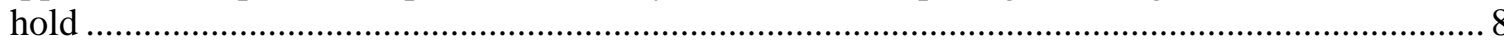

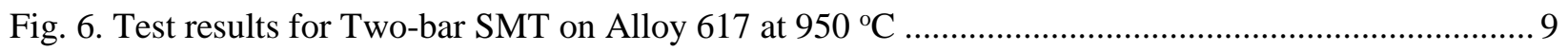

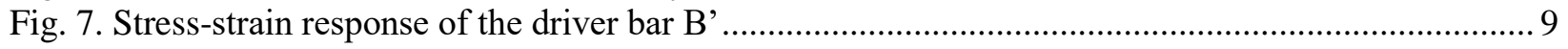

Fig. 8. Picture of Alloy 617 specimens after the two-bar SMT test..................................................... 10

Fig. 9. Schematics of the single smooth bar SMT setup ..................................................................... 11

Fig. 10. Hysteresis loops of single smooth bar SMT on SS316H at different strain ranges ...................... 11

Fig. 11. Picture of the SS316 specimen after the single smooth bar SMT scope tests at $815{ }^{\circ} \mathrm{C} \ldots \ldots \ldots \ldots \ldots 12$

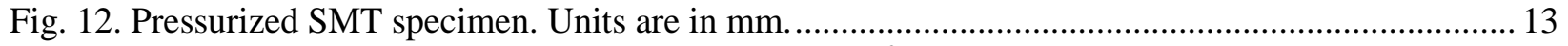

Fig. 13. Pressurized SMT test results for Inc617-P10 at $950{ }^{\circ} \mathrm{C}$ (internal pressure is $1.03 \mathrm{MPa}$ ) .............. 14

Fig. 14. Type 1 SMT solid bar specimen geometry for SS316H. Units are in mm. .............................. 15

Fig. 15. Hold time effect on the maximum stresses of Type 1 SMT on SS316H with $0.3 \%$

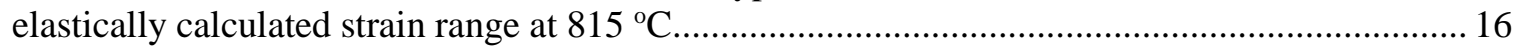

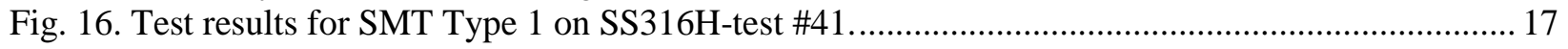

Fig. 17. Test results for SMT Type 1 on SS316H-test \#43 ................................................................ 18

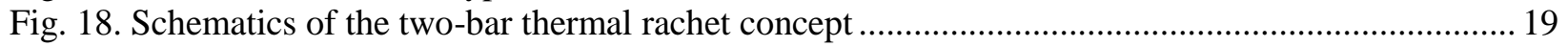

Fig. 19. Two-bar system simulates a pressure vessel with cyclic internal pressure ................................ 19

Fig. 20. Two-bar system simulates a pressure vessel with cyclic bending ...........................................20

Fig. 21. Schematics of the anti-phase thermomechanical fatigue for one cycle .....................................2 21

Fig. 22. Thermo-mechanical fatigue on Alloy 617 at temperature range of 350 to $950{ }^{\circ} \mathrm{C} \ldots \ldots \ldots \ldots \ldots \ldots \ldots . . . . . . . . .22$

Fig. 23. Representative hysteresis loops and stress vs. temperature curves for the thermomechanical fatigue on Alloy 617 at temperature range of 350 to $950{ }^{\circ} \mathrm{C}$...........................22

Fig. 24 Picture of the failed Alloy 617 specimen after thermomechanical fatigue.................................. 22 


\section{LIST OF TABLES}

Table 1. Chemical compositions of Alloy 617 plate with heat number 314626 (weight \%)...................... 3

Table 2. Chemical compositions of SS316H bar with heat number 101076 (weight \%) ........................... 3

Table 3. Results on pressurized SMT for Alloy 617 with tension hold ............................................... 14

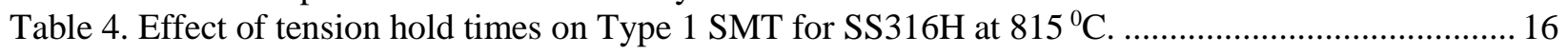




\section{ACRONYMS}

$\begin{array}{ll}\text { ART } & \text { Advanced Reactor Technologies Program } \\ \text { ASME } & \text { American Society of Mechanical Engineers } \\ \text { B\&PV } & \text { Boiler and Pressure Vessel } \\ \text { CC } & \text { Code Case } \\ \text { CF } & \text { Creep-Fatigue } \\ \text { DOE } & \text { Department of Energy } \\ \text { EPP } & \text { Elastic-Perfectly Plastic } \\ \text { ORNL } & \text { Oak Ridge National Laboratory } \\ \text { SMT } & \text { Simplified Model Test }\end{array}$




\section{ACKNOWLEDGMENTS}

The research was sponsored by the U.S. Department of Energy, under contract No. DE-AC05-

00OR22725 with Oak Ridge National Laboratory (ORNL), managed and operated by UT-Battelle, LLC, and under Contract No. DE-AC02-06CH11357 with Argonne National Laboratory (ANL), managed and operated by UChicago Argonne, LLC. Programmatic direction was provided by the Office of Nuclear Energy.

The authors gratefully acknowledge the support provided by Alice Caponiti, Director, Office of Advanced Reactor Technologies (ART), Sue Lesica, Federal Manager, ART Advanced Materials Program, and Hans Gougar of Idaho National Laboratory (INL), National Technical Director, ART GasCooled Reactors Campaign.

Technical support from C. Shane Hawkins, Seth T. Baird and Eric C. Disney of ORNL is acknowledged. The time spent by Lianshan Lin, Hong Wang and Edgar Lara-Curzio of ORNL in reviewing this report is greatly appreciated. 


\begin{abstract}
Experiments in support of the development of the integrated Elastic Perfectly-Plastic (EPP) analysis with the Simplified Model Test (SMT) design method continued in FY18. The goal of this integrated design method is to incorporate a SMT data-based approach for creep-fatigue damage evaluation into the EPP methodology to avoid the separate evaluation of creep and fatigue damage and eliminate the requirement for stress classification in current methods; thus, greatly simplifying evaluation of elevated temperature cyclic service.

Two innovative SMT based creep fatigue experimental methods were fully developed in FY18 and are documented in this report. These newly-developed SMT test methods have resolved all the critical challenges in the original SMT key feature article testing and enable the potential of further development of the SMT based creep fatigue evaluation method into a standard testing method. This report also summarizes the recent test results for the Type 1 SMT key feature testing on SS316H with long hold times, the pressurization SMT on Alloy 617 at low strain range and thermomechanical experiments on Alloy 617.
\end{abstract}




\section{BACKGROUND}

The technical basis of the current simplified design rules in Division 5 Appendix HBB-T of ASME's Boiler and Pressure Vessel Code for the evaluation of strain limits and creep-fatigue damage was based on elastic analysis with the assumption that plasticity and creep can be uncoupled. These rules have been deemed inappropriate for designs at high temperatures because it is not feasible to decouple plasticity and creep for materials at the service temperatures of the High Temperature Gas Cooled Reactor (HTGR) as well as the Very High Temperature Reactor (VHTR).

The Elastic-Perfectly Plastic (EPP) cyclic service code cases, strain limits code case (N-861) and EPP creep-fatigue code case (N-862), address these issues in that they are applicable at very high temperatures. The EPP methods also greatly simplify the design evaluation procedure by eliminating the need for stress classification that is the basis of the current simplified design rules. However, the EPP code case for evaluation of creep-fatigue damage still requires the separate evaluation of creep damage and fatigue damage by placing a limit on the allowable combined damage, the $\mathrm{D}$ diagram, based on the calculated individual damages. The uncertainties in the separate evaluation of the creep damage and fatigue damage from the test data lead to the use of overly conservative design factors in the current creep-fatigue procedure. The difficulties and approximations in the D diagram approach for creep fatigue evaluation are what led to the development of the Simplified Model Test or SMT methodology. The SMT approach is an alternative creep fatigue evaluation approach that it is no longer necessary to use the damage interaction, or D diagram. The reason is that the combined effects of creep and fatigue are accounted for in the test data by means of a SMT specimen that is designed to replicate or bound the stress and strain redistribution that occurs in actual components when loaded in the creep regime.

The goal of the integrated EPP-SMT design approach is to incorporate a SMT data-based approach for creep-fatigue (CF) damage evaluation into the EPP methodology to avoid the use of the D diagram and to minimize over-conservatism while properly accounting for localized defects and stress risers. A detailed plan has been developed and revised for the development of this EPP-SMT methodology (Wang et al., 2016a, 2016b, 2017a, 2018 and Messner, 2018). The key elements in the development of this integrated approach include 1) the development of SMT creep fatigue evaluation approach, 2) bounding the EPP strain ranges for the SMT key feature test specimens and realistic structural components, 3) the development of the creep fatigue design curve with the effect of elastic follow-up, primary load, hold time effect and multi-axiality, and 4) additional considerations for welds and the environmental effect such as corrosion, thermal aging and radiation on the creep fatigue design life.

Experimentally, SMT key feature creep fatigue testing has been fully developed and successfully tested for Alloy 617, SS316H, SS304H and Gr. 91 (Wang, et al., 2013a, 2014, 2015, 2016a, 2017b, 2017c). The testing of the SMT key feature creep fatigue test articles was designed to evaluate the effect of elastic follow-up factor, stress concentration factor, primary load, strain range, loading rate, test temperature and hold time. The test data were used to verify the EPP creep fatigue code case and for the development of materials constitutive models. However, in the process of developing this EPP-SMT method, the strain range evaluations of the SMT key feature test specimens were found to be difficult. The stress and strain redistribution for the SMT key feature test articles was complex and the specimens most often did not fail inside the gage section. Thus, the development of EPP+SMT method has led to major effort in improvement of the SMT based testing that allows the effect of elastic follow-up to be evaluated without imposing complications for theoretical analysis, which also fits in the broader goal of the development SMT creep fatigue evaluation methodology.

In this reporting period, two new SMT test methods, two-bar SMT and single smooth bar SMT are developed and scope tested successfully with standard creep fatigue test specimens and instrumentation. These newly developed SMT based test methods and test protocols overcome many challenges of 
conducting SMT experiments. It also points to the prospect of the potential of establishing ASTM test standard for the practical implementation of the test techniques to allow SMT data be generated without specialized equipment and highly skilled technical experts as required by the SMT key feature testing.

Additionally, in support of integrated EPP-SMT design methods development, SMT key feature testing on Alloy 617 pressurized tubular specimens and SS316H solid bar specimens continued in FY18 to evaluate the effect of primary load and hold time to establish the basis for the development of SMT based design curve. Further, lab key feature testing representative of pressurized reactor vessels was extended to much more complex loading conditions. Standard thermomechanical experimental data were also generated on Alloy 617 to support the development of a material model at Argonne National Laboratory (ANL). 


\section{MATERIALS}

All the Alloy 617 specimens were machined out of the Alloy 617 plate with Heat No. 314626 from ThyssenKrupp VDM USA, Inc. The plate has a nominal thickness of $38 \mathrm{~mm}$. The chemical composition of the plate is listed in Table 1. The specimen longitudinal direction is oriented along the rolling direction of the plate. All the specimens were tested in the as-received condition.

Table 1. Chemical compositions of Alloy 617 plate with heat number 314626 (weight \%).

\begin{tabular}{c|c|c|c|c|c|c|l|l|l|l|l|c}
\hline $\mathbf{C}$ & $\mathbf{S}$ & $\mathbf{C r}$ & $\mathbf{N i}$ & $\mathbf{M n}$ & $\mathbf{S i}$ & $\mathbf{M o}$ & $\mathbf{T i}$ & $\mathbf{C u}$ & $\mathbf{F e}$ & $\mathbf{A l}$ & $\mathbf{C o}$ & $\mathbf{B}$ \\
\hline 0.05 & $<0.002$ & 22.2 & $\mathrm{R} 54.1$ & 0.1 & 0.1 & 8.6 & 0.4 & 0.04 & 1.6 & 1.1 & 11.6 & $<0.001$ \\
\hline
\end{tabular}

SS316H round bar material with nominal diameter of $25.4 \mathrm{~mm}$ was purchased from Outokumpu Stainless Bar, LLC. The heat number is 101076 and the as-received SS316H bar satisfies specification ASME SA497. The chemical composition of the SS316H is listed in Table 2. All the specimens were tested in the as-received condition.

Table 2. Chemical compositions of SS316H bar with heat number 101076 (weight \%)

\begin{tabular}{c|c|c|c|c|c|c|c|c|c|c}
\hline $\mathbf{C}$ & $\mathbf{P}$ & $\mathbf{S i}$ & $\mathbf{N i}$ & $\mathbf{M n}$ & $\mathbf{N}$ & $\mathbf{T i}$ & $\mathbf{S n}$ & $\mathbf{V}$ & $\mathbf{F e}$ & $\mathbf{C b}-\mathbf{T a}$ \\
\hline 0.045 & 0.028 & 0.650 & 10.120 & 1.420 & 0.053 & 0.002 & 0.006 & 0.060 & balance & 0.014 \\
\hline $\mathbf{S}$ & $\mathbf{C r}$ & $\mathbf{C o}$ & $\mathbf{M o}$ & $\mathbf{C b}$ & $\mathbf{A l}$ & $\mathbf{B}$ & & & & \\
\hline 0.024 & 16.230 & 0.279 & 2.090 & 0.014 & 0.004 & 0.004 & & & & \\
\hline
\end{tabular}

\section{DEVELOPMENT OF SMT TEST METHODOLOGY}

The original SMT key feature test articles, i.e., Type 1 SMT, Type 2 SMT and pressurized tubular SMT (Wang, et al., 2013a, 2014) were sized to include key features of a real structure with elastic follow-up and stress concentrator. The specimens have two sections with two different cross-sectional areas and with a transition region designed to connect these two section and to represent a stress riser. The elastic follow-up effects in these test articles were provided through the elastic energy stored in the thicker or the driver section of the specimen. In order to achieve desired elastic follow-up factors, the length ratios of the driver section to the test section will need to be varied for a structure with specified area ratio. Thus, the test specimens are usually large in length. For example, the Type 1 SMT solid bar specimen has a total length of $482 \mathrm{~mm}$ with an effective dual gage section of $127 \mathrm{~mm}$. In addition to the special specimen geometry, testing of these SMT key feature articles also requires specialized instrumentation such as large heater furnace to achieve uniform temperature along the specimen length and customized extensometers to allow precise displacement-controlled SMT creep-fatigue testing. In reviewing the SMT key feature testing results to support the development of EPP-SMT design approach, the complex material responses to SMT key feature testing imposed major difficulties in extracting information from these tests to verify the EPP analysis. In order to resolve these issues and support the development of SMT based creep fatigue evaluation methodology, new SMT test methods are developed in FY18, and these methods are explained below.

\subsection{TWO-BAR SMT METHOD}

The transition region between the driver section and the test section in the SMT key feature test articles has two functions, 1) it creates a key feature that can represent a stress riser in a component due to stress concentration, and 2) it effectively decreases the elastic follow-up factor. The decrease of elastic followup factor by adding the transition region will require the test specimens to be designed longer in length, 
which is not desirable for the experimental process. More importantly, the stress and strain in this transition region and their redistribution during testing are quite complex for the SMT key feature test articles, and they are difficult, if not impossible to measure experimentally. Several SMT key feature test specimens also failed at the root of the transition radius instead of the uniform test gage section. Therefore, the immediate task to generate SMT based design curve is to develop a new method to allow the evaluation of the effect of the elastic follow-up without the transition region and ensure failure inside the uniform test gage section, which has led to the concept of two-bar SMT method. The idea is schematically shown in Fig. 1, where driver section is defined as bar B and the test section is bar A. Because the two sections are in series in the load train for SMT, the load of the driver bar B is the same as the load of the test bar A for SMT. For SMT based two-bar model, the two bars would be placed in two electronically coupled machines with the controls to allow the load of the two bars to be equal.

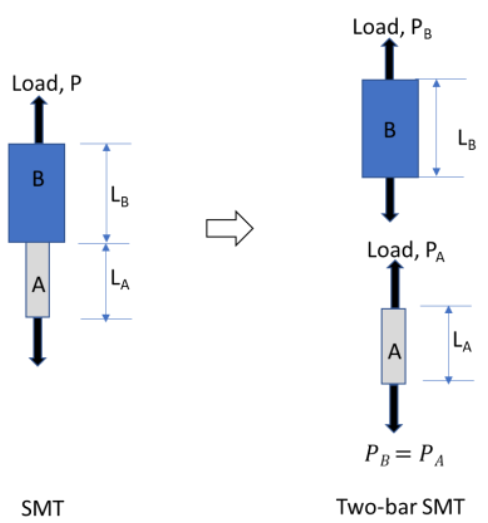

Fig. 1. Schematics of the SMT specimen and two-bar SMT representation

The following explains the design concept of the two-bar SMT experiment and the method to determine the initial experiment parameters. The stress-strain relationships for standard creep fatigue and creep fatigue with elastic follow-up are schematically shown in Fig. 2. Referring to Fig. 2, the elastic follow-up may be quantified by computing the ratio of $\varepsilon_{0-2}$, the creep strain in the test section including elastic follow-up, to the creep strain that would have occurred under pure relaxation, $\varepsilon_{0-1}$. Thus, the elastic follow-up, $q$, is given by

$$
q=\frac{\varepsilon_{0-2}}{\varepsilon_{0-1}}
$$

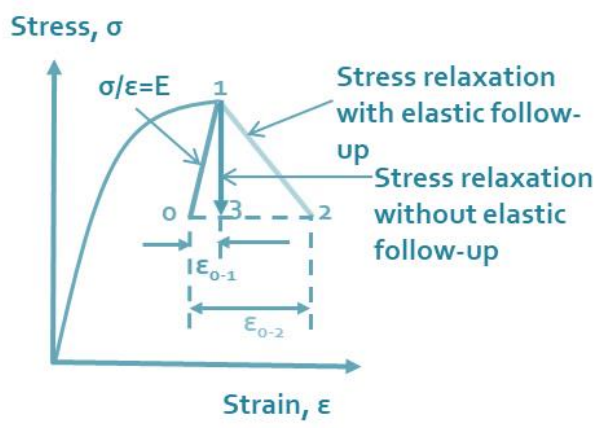

Fig. 2. Stress-strain curves with elastic follow-up 
By definition, the elastic follow-up factor is a quantity equal or larger than 1 . The elastic follow-up factor equals to 1 for standard strain-controlled creep fatigue tests. Conventionally, standard creep fatigue testing (i.e., with elastic follow-up factor of 1) is referred as testing without elastic follow-up effect. For structures with elastic follow-up effect, they experience larger strains with displacement-controlled loading than would be predicted using an elastic analysis. The relaxation curve with elastic follow-up for the test bar A, i.e., the slope of the segment 1-2 is

$$
\text { slope }=\frac{d \sigma_{A}}{d \varepsilon_{A}}=\frac{-E_{A}}{q-1}
$$

Since the two bars are placed on separate machines, the driver bar B can be at a different temperature. To simplify the design, the driver bar can be at room temperature, i.e., the driver bar B is elastic and it follows:

$$
\dot{\varepsilon_{B}}=\frac{\dot{\sigma_{B}}}{E_{B}}
$$

where $\dot{\varepsilon}$ is the strain rate, $\sigma$ is the stress, $E$ is the elastic modulus, $\dot{\sigma}$ is the stress relaxation rate.

The two bars are viewed as elastic springs with different stiffness, $K$. And at the beginning of the hold segment prior to stress relaxation, the load and displacement relationships for each bar can be expressed as

and

$$
\text { load_A }=K_{A}{ }^{*} \varepsilon_{A}{ }^{*} L_{A}
$$

$$
\text { load_B }=K_{B}{ }^{*} \varepsilon_{B}{ }^{*} L_{B}
$$

with

$$
K=\frac{E * \alpha}{L}
$$

where $\varepsilon$ is the strain, $\alpha$ is the cross-sectional area and $L$ is the gage length of each bar. Experimentally, the $L$ is determined by the gage lengths of the extensometer that are placed on the bars. The driver bar, B remains elastic during the entire loading process.

For the SMT configuration, the total load in the driver bar is the same as the test sectio during the test, i.e.,

$$
\text { load_A }=\text { load_B }
$$

During constant displacement hold,

$$
\varepsilon_{A} * L_{A}+\varepsilon_{B} * L_{B}=\text { constant amplitude }
$$

which is the equivalent to the expression below in terms of strain rate:

$$
\dot{\varepsilon_{A}} * L_{A}+\dot{\varepsilon_{B}} * L_{B}=0
$$

By combining equations (9) and (2), (3), and assuming the cross-sectional area of the two bars are $\alpha_{A}$ and $\alpha_{B}$, 


$$
\frac{d \sigma_{A}}{d \varepsilon_{A}}=\frac{d\left(\sigma_{B *} \alpha_{B} / \alpha_{A}\right)}{d \varepsilon_{A}}=\frac{E_{B} \dot{\varepsilon}_{B}}{\dot{\varepsilon}_{A}} * \frac{\alpha_{B}}{\alpha_{A}}=\frac{E_{B}}{\dot{\varepsilon}_{A}} * \frac{\alpha_{B}}{\alpha_{A}} * \frac{-\dot{\varepsilon}_{A}}{L_{B}} * L_{A}=\frac{-E_{A}}{q-1}
$$

Therefore, the elastic follow-up factor, $q$, can be expressed as

$$
q=1+\frac{\boldsymbol{E}_{A^{*}} \boldsymbol{\alpha}_{A}}{L_{A}} * \frac{L_{B}}{\boldsymbol{E}_{B} * \boldsymbol{\alpha}_{B}}
$$

which can be further simplified to the following when combined with equation (6),

$$
q=1+\frac{K_{A}}{K_{B}}
$$

Equation (12) shows that the designed elastic follow-up factor, $q$, is independent of the creep rate of the test bar A when the driver bar B is elastic, i.e., by setting this driver bar at room temperature. For a given SMT specimen at high temperature, one can design SMT test with different elastic follow-up factors by simply changing the driver bar spring constant, $K_{B}$.

A further simplified concept is to use a standard creep fatigue specimen for the driver bar, $B^{\prime}$, but impose electronic constants, $C_{l}$ to the load and $C_{2}$ to the strain signals to allow it to function equivalently as the driver bar $B$ instead of physically changing its geometry. In this simplified two-bar method, equations (7), (8) and (12) are modified into (13), (14) and (15), respectively.

$$
\begin{gathered}
\text { load_B }=C_{1} * \text { load_B' } B^{\prime} \\
C_{2} * \varepsilon_{B}{ }^{\prime} * L_{B^{\prime}}+\varepsilon_{A} * L_{A}=\text { constant amplitude } \\
q=1+\frac{K_{A} *\left(\frac{C_{1}}{K_{B}}\right)}{C_{2}}
\end{gathered}
$$

This new two-bar concept provides two major advantages: 1) it is versatile in achieving different elastic follow-up factor and 2) it is no longer necessary to use a large driver bar to achieve the elastic follow-up in the test bar, hence removes the demands in the required large heating source for the SMT experimental setup. The key of this two-bar SMT concept is to design the control parameters to allow the elastic energy stored in this driver bar to produce the desired elastic follow-up factor in the test bar.

The two-bar SMT setup is schematically shown in Fig. 3. The two bars are placed in two electronically coupled servo-hydraulic machines with one bar serves as the driver section at room temperature and one bar as the test section. In this case, the driver bar B' is connected to the strain-controlled machine and the test bar A is connected to the load-controlled machine. Equation (15) was used to define the elastic follow-up factor for the test bar A. The relationships of the load and strain signals between the two bars are defined through the control logic and they satisfy equations (7), (13) and (14). The two strain components with one from test bar A, $\varepsilon_{A}$, and the second strain $\varepsilon_{B}$ converted from driver bar B' are combined with a signal summing box and then summed strain is used as the corresponding command signal for the strain-controlled controller. A LabVIEW program was used to automate and enddisplacement waveform and applied to the strain controller to perform the two-bar SMT creep fatigue experiments. 


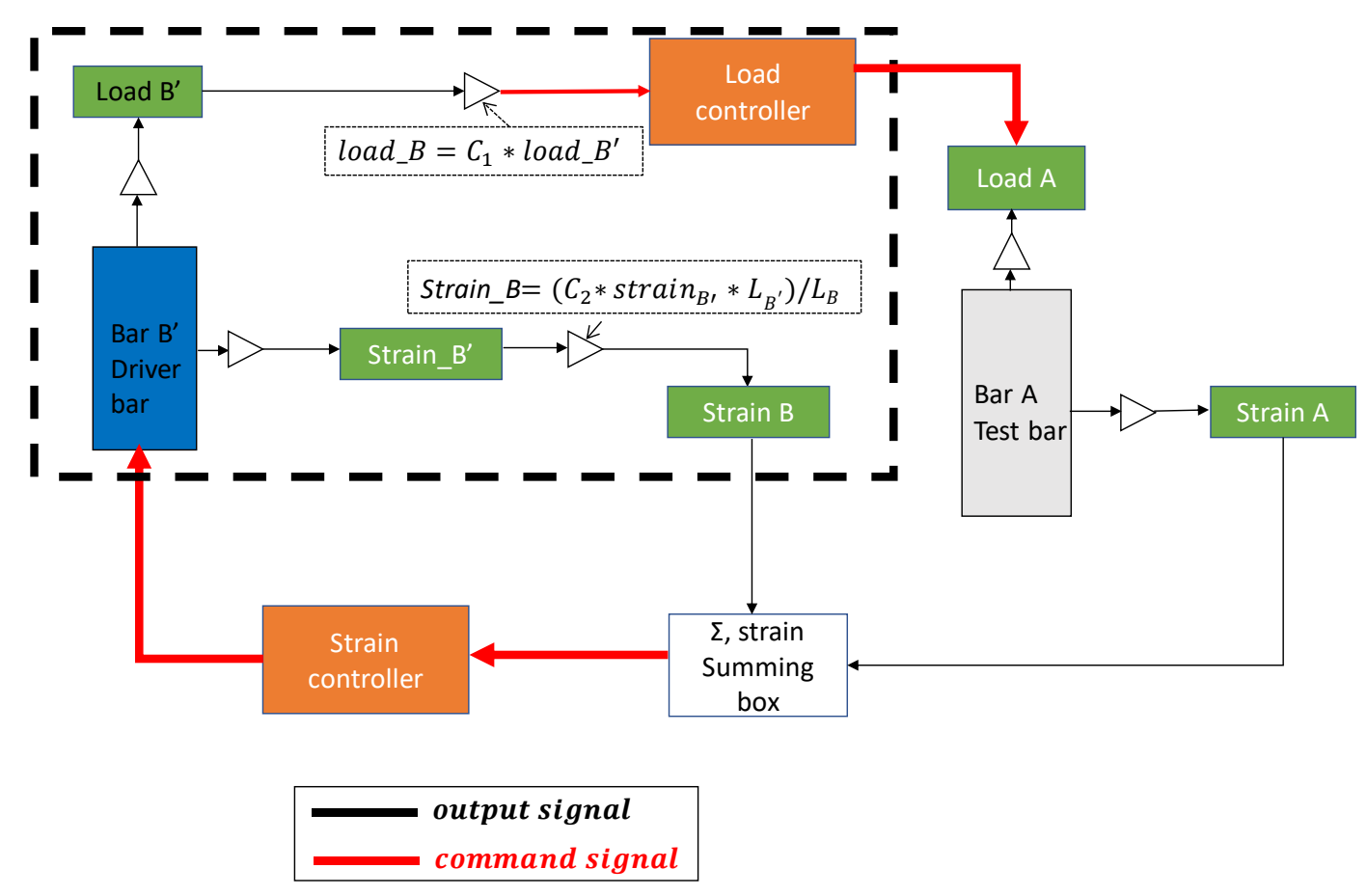

Fig. 3. Schematics of the two-bar SMT setup

The procedure for performing the two-bar SMT test is the same as the standard creep fatigue. To design a test with a different elastic follow-up factor, the signal amplifier constants for the load and strain signals, $C_{1}$ and $C_{2}$, will be adjusted accordingly, and the process does not need to physically change the geometry of driver bar B'. This simplified two-bar SMT concept was tested on Alloy 617 at $950{ }^{\circ} \mathrm{C}$ using the standard creep fatigue specimen geometry shown in Fig. 4. For this test, the designed elastic follow-up factor was 3. The applied end-displacement waveform is schematically shown in Fig. 5. The loading was fully reversed, and the hold time was $600 \mathrm{~s}$. The specimen was loaded to $0.457 \mathrm{~mm}$ total displacement in $3 \mathrm{~s}$, unloaded to $-0.457 \mathrm{~mm}$ in $6 \mathrm{~s}$ before returning it to zero displacement. It is designed to be tested for a similar condition as tests \#17 and \#18 performed for the Type 1 SMT (Wang et al., 2015).

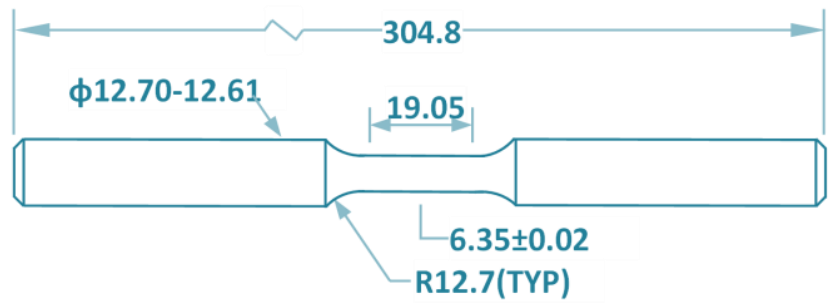

Fig. 4. Geometry of the standard creep fatigue specimen. Units are in $\mathbf{~ m m . ~}$ 


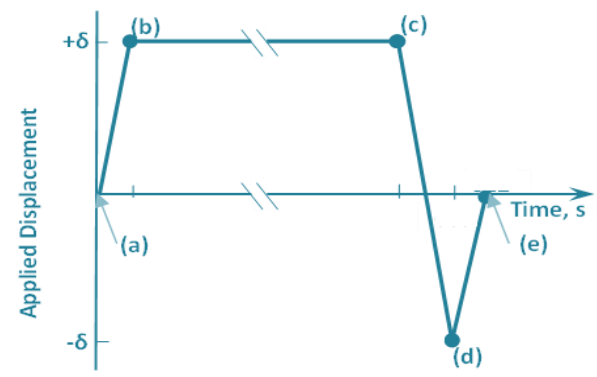

Fig. 5. Applied end-displacement profile for one cycle of SMT creep-fatigue testing with tension hold

Plots of representative hysteresis loops, maximum and minimum stresses and strains and strain ranges of the test bar A are presented in Fig. 6. An elastic follow-up factor of 3 was achieved for this test. It was found that there was a remarkable difference in the noise level of the data between this new two-bar SMT and the original Type 1 or Type 2 SMT key feature tests, with the original SMT tests being significantly noisier. Therefore, two-bar SMT method can be used to produce high quality SMT based creep fatigue test data.

The stress-strain responses from the driver bar B are shown in Fig. 7, and it was confirmed that this specimen remained elastic and the slope of the stress-strain curve corresponded to be the elastic modulus of the material at room temperature.

The number of cycles to failure for this test was 900, which is consistent with the results from tests \#17 and \#18 performed for Type 1 SMT (Wang, et al., 2015). This two-bar SMT precisely captures the effect of elastic follow without previously observed significantly ratcheting strain in the SMT key feature tests, therefore eliminating this critical issue when using the data for design analysis. The test specimen failed inside the gage section and a picture of the two specimens after testing is shown in Fig. 8. A red arrow identifies the failure location of the test bar A. Since the driver bar remained elastic, it did not experience any physical changes after testing. 


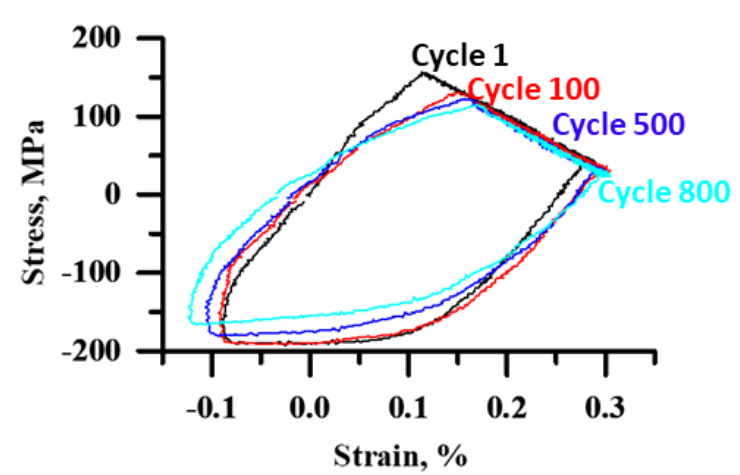

(a) hysterysis loops

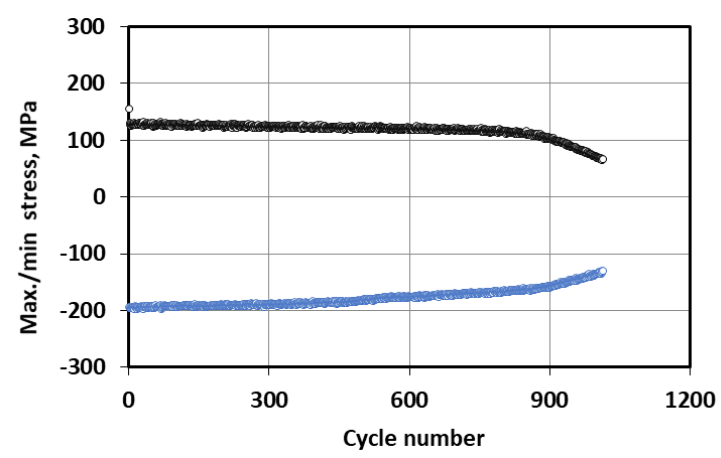

(c) Maximum and minimum stresses

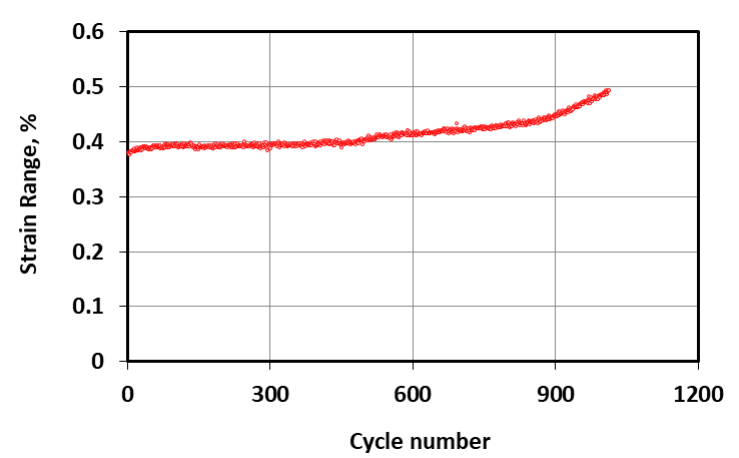

(b) strain range

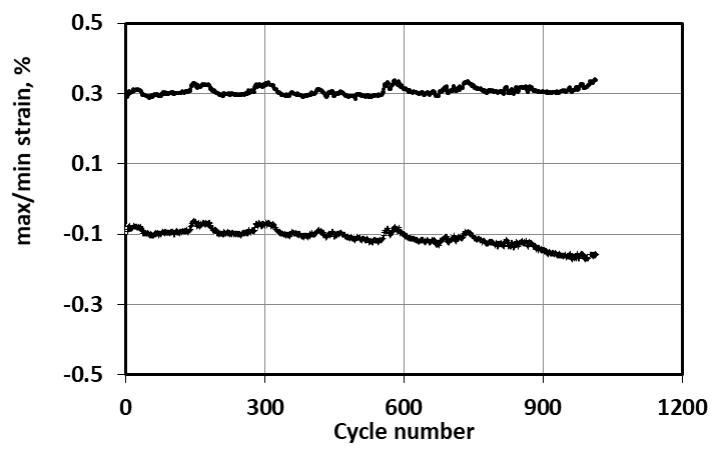

(d) Maximum and minimum strains

Fig. 6. Test results for Two-bar SMT on Alloy 617 at $950{ }^{\circ} \mathrm{C}$

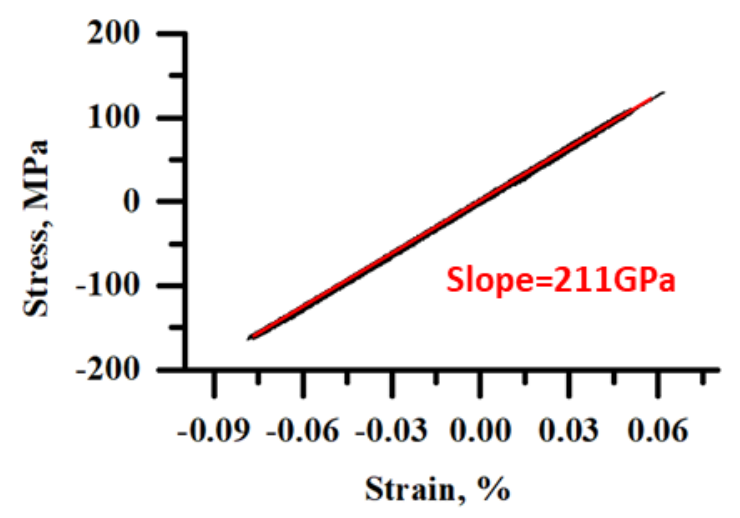

Fig. 7. Stress-strain response of the driver bar B' 


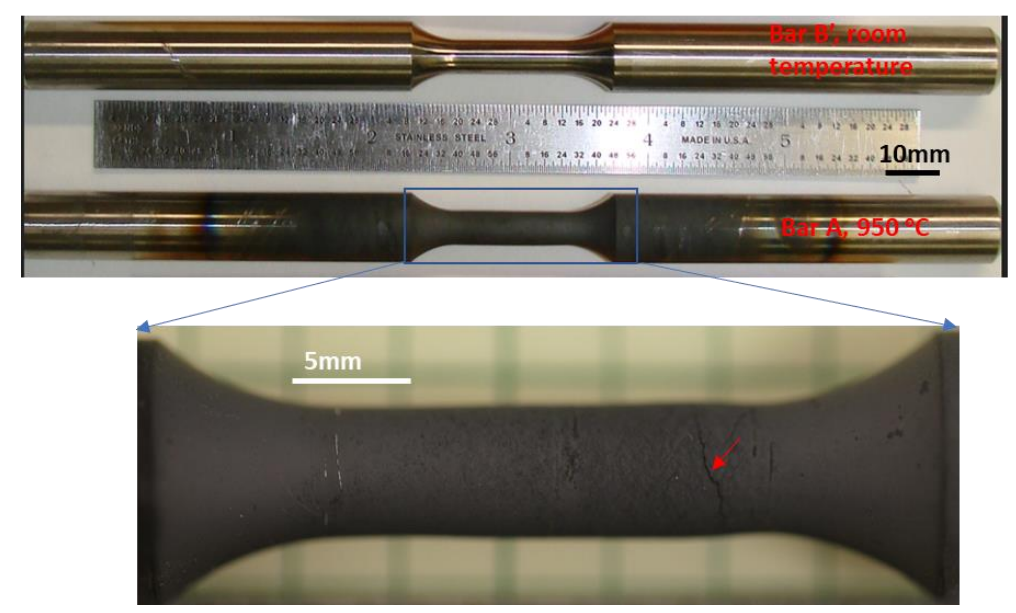

Fig. 8. Picture of Alloy 617 specimens after the two-bar SMT test

\subsection{SINGLE SMOOTH BAR SMT}

The above two-bar SMT concept has been successfully implemented, but it still requires two servohydraulic machines coupled together to perform one SMT test. The complex experimental setup is not ideal for a standard testing practice. Thus, the next step in the development of this new SMT method is to be able to perform the test on a single servo-hydraulic machine, much like the standard creep fatigue procedure, i.e., the development of this single smooth bar SMT method.

What makes this single smooth bar SMT possible is that the two-bar SMT test design is based on the principle that the driver bar is fully elastic. The elastic behavior significantly simplifies the design because the displacement or strain signal can be directly generated from the measured load signal using an electronic amplifier. This amplifier is determined by the relationships described in equations (4), (5), (7) and (9) for a test with a designed elastic follow-up factor. This single smooth bar SMT set up principle is schematically illustrated in Fig. 9. In this case, the load signal from this test bar is converted to an equivalent strain signal, $\varepsilon_{B}$, to represent the strain component from the elastic driver bar B. Instead of using a second servo-hydraulic machine, the components associated with the elastic driver bar (shown within the dashed box in Fig. 3) are replaced with this electronic converted signal. This new setup greatly simplified the complexity of a SMT experiment.

To implement this single bar SMT concept, scope tests were performed on a SS316H standard creep fatigue specimen at $815^{\circ} \mathrm{C}$. This specimen has pre-existed loading history (it was slightly thermomechanical cycled), but it is in a good condition for scope testing purposes. The test was designed to have an elastic follow-up factor of 3.4. The specimen was cyclic loaded at different strain ranges using the end-displacement profile shown in Fig. 5 with a peak tension hold of 600s. The representative hysteresis loops with at least 12 cycles at each strain ranges are plotted in Fig. 10. It is evidently shown that the single smooth bar SMT scope tests were successfully carried out for all the tested strain ranges from lower level of $0.27 \%$ to large level of $1.23 \%$. The slopes of stress relaxation segment are the same for all strain ranges, confirming that the elastic follow-up was controlled and remained independent of testing strain ranges. The results have therefore verified the design concept for single smooth bar SMT. It is worth mentioning that similar to two-bar SMT, these single smooth bar SMT scope tests provided good quality data with very high signal-to-noise ratio. 


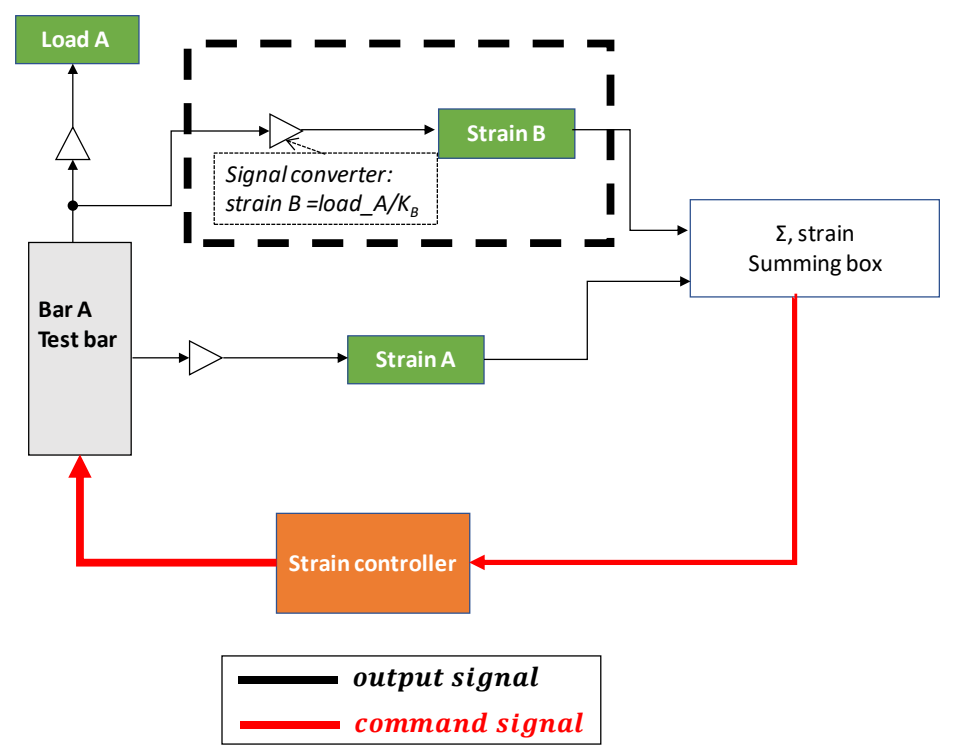

Fig. 9. Schematics of the single smooth bar SMT setup

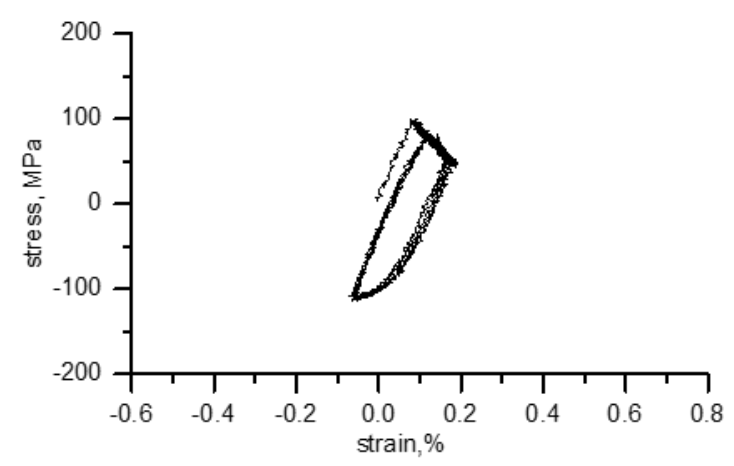

(a) strain range of $0.27 \%$

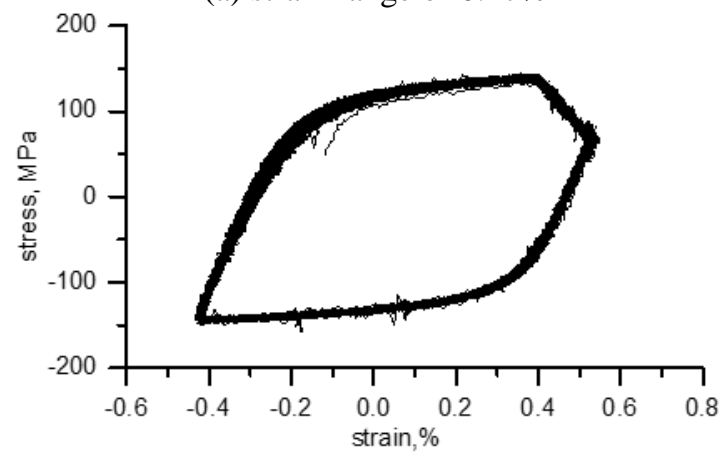

(c) strain range of $0.96 \%$

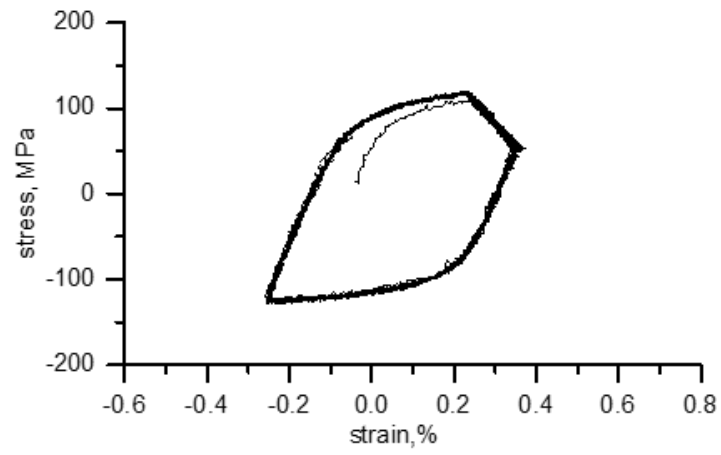

(b) strain range of $0.62 \%$

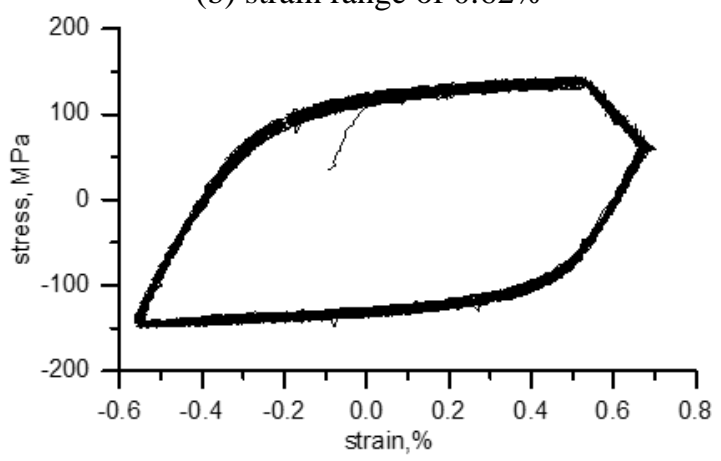

(d) strain range of $1.23 \%$

Fig. 10. Hysteresis loops of single smooth bar SMT on SS316H at different strain ranges 
The specimen was tested to failure at the large strain range of $1.23 \%$ and a picture of the failed specimen is shown in Fig. 11. The specimen failed inside the gage section without signs of barreling. The single smooth bar SMT concept is therefore verified.

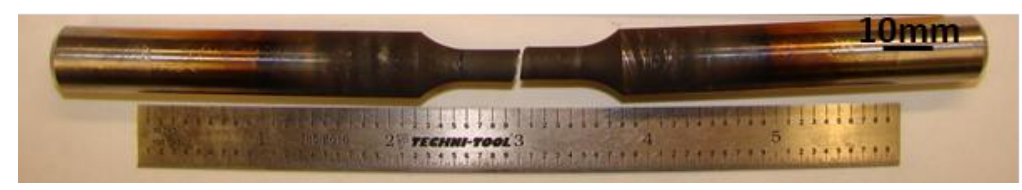

Fig. 11. Picture of the SS316 specimen after the single smooth bar SMT scope tests at $815{ }^{\circ} \mathrm{C}$

It is noted that the setup for single smooth bar SMT is similar to the standard creep fatigue test described in ASMT E2714. The major difference is the addition of the electronic component for generating the equivalent strain signal for the elastic driver bar from the measured load and then combining it with the strain from the test specimen to form the control strain signal. However, these features can be implemented relatively easily with most analog or digital controllers. The testing procedure and requirements are the same as the ASMT E2714. Thus, this single smooth bar SMT method has the potential to be further developed in to an ASTM standard procedure for the high temperature design community to use as an alternative creep fatigue evaluation method.

\section{PROGRESS IN SMT KEY FEATURE TESTING}

\subsection{SMT PRESSURIZATION TESTING ON ALLOY 617 AT LOW STRAIN RANGE}

SMT pressurization tests are being used to assess whether the effects of stress levels associated with sustained primary loads will be small and can be neglected when compared to the cyclic secondary and peak levels for the development of SMT creep-fatigue based design curve. The primary load is introduced by the internal pressure in the tubular SMT specimen (Wang, et al., 2015, 2016b, 2017). The tubular specimen geometry is shown in Fig. 12. The driver section, test section and the transition region are the same as previously pressurization SMT specimen used in Wang et al., (2015, 2016b, 2017). There are slightly modifications to the connection tabs for easier specimen machining and welding of the tab extensions. The total controlled specimen length is $127 \mathrm{~mm}$ for SMT experiment, the same as previous pressurization SMT. 


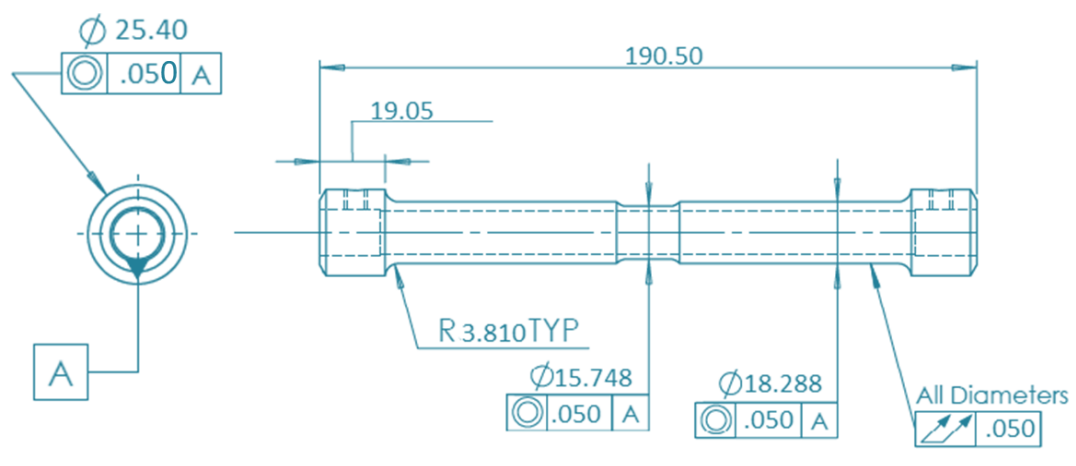

Fig. 12. Pressurized SMT specimen. Units are in $\mathbf{m m}$.

In FY17 (Wang, et al., 2017a), it was concluded from the SMT pressurization test results at larger strain range that the SMT creep fatigue life is not dependent on the primary stress level when the test is performed with the internal pressure less than the allowable level of $\sim 1.03 \mathrm{MPa}$ (or $150 \mathrm{psi}$ ) for Alloy 617 at $950{ }^{\circ} \mathrm{C}$.

In FY18, the effect of primary stress on SMT creep fatigue life was evaluated at a low strain range. The test was performed using a tension hold loading profile shown in Fig. 5 with a loading and unloading strain rate of approximately $4 \mathrm{E}-4 \mathrm{~s}^{-1}$. The hold time at peak tension was 600s. In literature, there are no reference creep fatigue test data available for Alloy 617 at this low strain range level. Test results on standard creep fatigue specimens at higher strain range of $0.3 \%, 0.6 \%$ and $1 \%$ at $950{ }^{\circ} \mathrm{C}$ for Alloy 617 are available from Idaho National Laboratory (INL) (refer to Carroll, et al., 2011). Based on the information from these standard creep fatigue and with the assumption that the creep damage would be larger at lower strain ranges than at higher strain ranges due to little stress relaxation at low strain ranges, the SMT creep fatigue life is extrapolated from the cycle life of large strain range data and estimated to be in the range of 30,000 cycles for a low strain range of $0.12 \%$.

This pressurized SMT specimen, INC617-P10 was cyclic loaded with an applied displacement amplitude of $0.025 \mathrm{~mm}$ (or $1 \mathrm{mil}$ ) and under the maximum allowable internal pressure of $1.03 \mathrm{MPa}$ (or $150 \mathrm{psi}$ ) at $950{ }^{\circ} \mathrm{C}$. The test parameters and results are summarized in Table 3 along with previous pressurization SMT on Alloy 617 with tension hold. The specimen has experienced 37,693 cycles at the time of writing this report, without showing signs of failure, which is longer than the estimated creep fatigue life of 30,000 cycles. It has thus confirmed that the primary stress introduced by the maximum allowable internal pressure of $1.03 \mathrm{MPa}$ (or $150 \mathrm{psi}$ ) has little or negligible impact on the SMT creep fatigue life at this low strain range.

Plots of the strain ranges and the maximum and minimum stresses and strains are shown in Fig. 13 for the available cycles for INC617-P10. The average strain measured at the necked test section did not change significantly but the overall trend showed ratcheting behavior to the compression direction. 


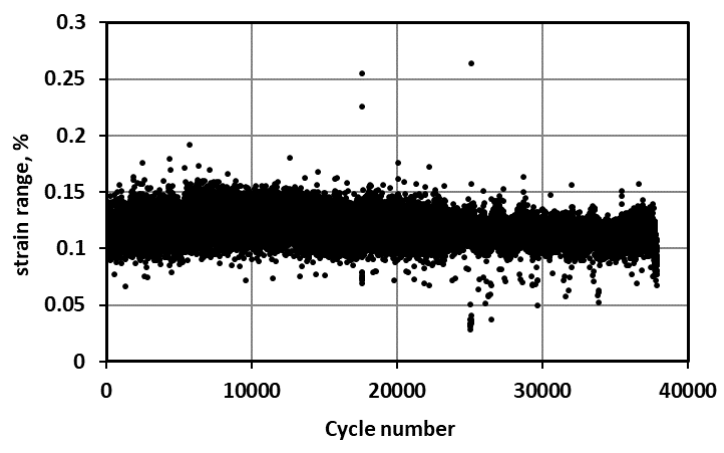

(a) Strain range

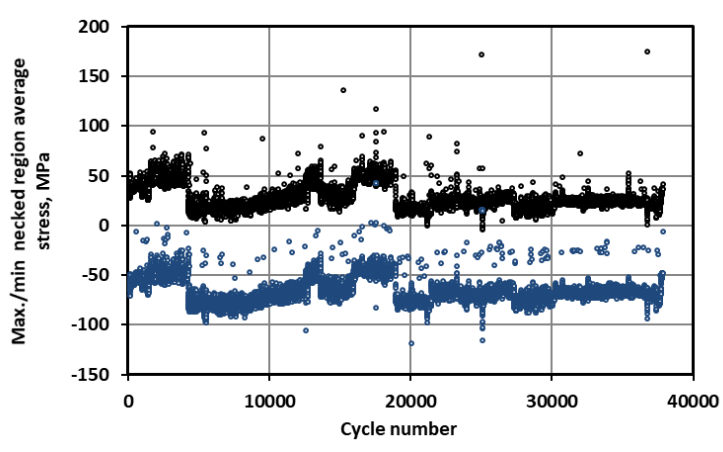

(b) Maximum and minimum stresses

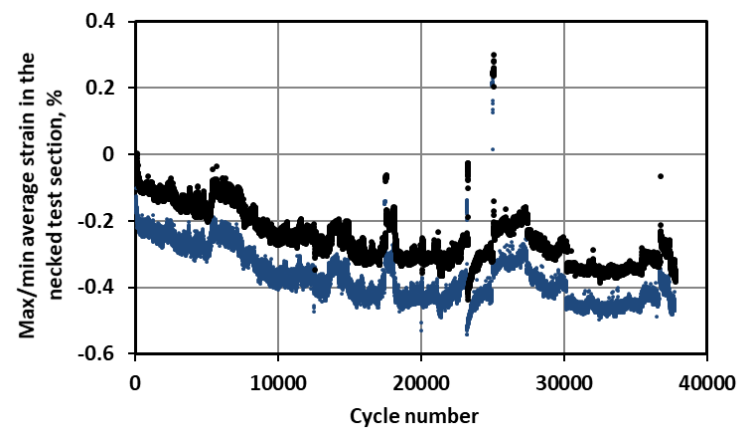

(c) Maximum and minimum strains

Fig. 13. Pressurized SMT test results for Inc617-P10 at $950{ }^{\circ} \mathrm{C}$ (internal pressure is 1.03MPa)

Table 3. Results on pressurized SMT for Alloy 617 with tension hold

\begin{tabular}{|c|c|c|c|c|c|c|}
\hline $\begin{array}{l}\text { Specimen } \\
\text { ID }\end{array}$ & $\begin{array}{c}\text { Amplitude, } \\
\delta \text { value }\end{array}$ & $\begin{array}{c}\begin{array}{c}\text { Initial strain } \\
\text { range }\end{array} \\
\end{array}$ & \begin{tabular}{|c} 
Test temperature \\
${ }^{\circ} \mathrm{C}$
\end{tabular} & Internal pressure & $\begin{array}{c}\text { Life time, } \\
\mathbf{h r}\end{array}$ & $\begin{array}{c}\begin{array}{c}\text { Cycles to } \\
\text { failure }\end{array} \\
\end{array}$ \\
\hline INC617-P01 & \multirow{5}{*}{$0.114 \mathrm{~mm}$ (or $4.5 \mathrm{mil})$} & $0.8 \%$ & 950 & $0.01 \mathrm{MPa}$ (or $2 \mathrm{psi}$ ) & 37.4 & 220 \\
\hline INC617-P02 & & $0.8 \%$ & 959 & $1.38 \mathrm{MPa}$ (or $200 \mathrm{psi}$ ) & 37.4 & 220 \\
\hline INC617-P04 & & $0.8 \%$ & 957 & 3.45MPa (or500 psi) & 34 & 200 \\
\hline INC617-P03 & & $0.75 \%$ & 958 & $5.17 \mathrm{MPa}$ (or $750 \mathrm{psi}$ ) & 25.5 & 150 \\
\hline INC617-P06 & & $0.8 \%$ & 950 & $5.17 \mathrm{MPa}$ (or $750 \mathrm{psi}$ & 23.8 & 140 \\
\hline INC617-P09 & $0.076 \mathrm{~mm}$ (or $3 \mathrm{mil})$ & --- & 953 & 5.17MPa (or $750 \mathrm{psi}$ & 54.4 & 320 \\
\hline INC617-P10 & $0.025 \mathrm{~mm}$ (or $1 \mathrm{mil})$ & $0.12 \%$ & 950 & $1.03 \mathrm{MPa}$ (or $150 \mathrm{psi})$ & $>6408$ & $>37,693$ \\
\hline
\end{tabular}

\subsection{HOLD TIME EFFECT ON TYPE 1 SMT-SS316H}

The goal of the EPP-SMT design methodology is to develop SMT based creep-fatigue design curves with extrapolation to hold times representative of operation conditions $(\sim 1,000 \mathrm{hr}$ of hold time). Longer hold times increase creep damage, whereas, fatigue dominates at short hold times. As the hold time is 
increased, the stress relaxation process saturates, the stress reaches to a constant value, and the straincontrolled creep-fatigue cycle life will approach saturation.

SMT creep-fatigue evaluation slows down stress relaxation process in a component due to the elastic follow-up effect, and therefore accelerates creep damage (Wang, et.al., 2013a). The evaluation of the effect of hold time on SMT creep fatigue cycle life is a necessary and important aspect in support of the developing of SMT based creep-fatigue design curves. During this reporting period, experiments were performed on SS316H on Type $1 \mathrm{SMT}$ at $815^{\circ} \mathrm{C}$ to provide test data in support of the development of SMT based design curve.

The Type 1 SMT is the same as in the previous study (Wang, et al., 2015, 2016b, 2017a) and the specimen geometry is shown in Fig. 14. The control length for the applied displacement was $127 \mathrm{~mm}$ (or 5") to achieve the designed elastic follow-up. The average strain was measured using a $10 \mathrm{~mm}$ gage extensometer placed inside the necked test section. The measured average axial strains in the necked test section were used to generate the hysteresis loops.

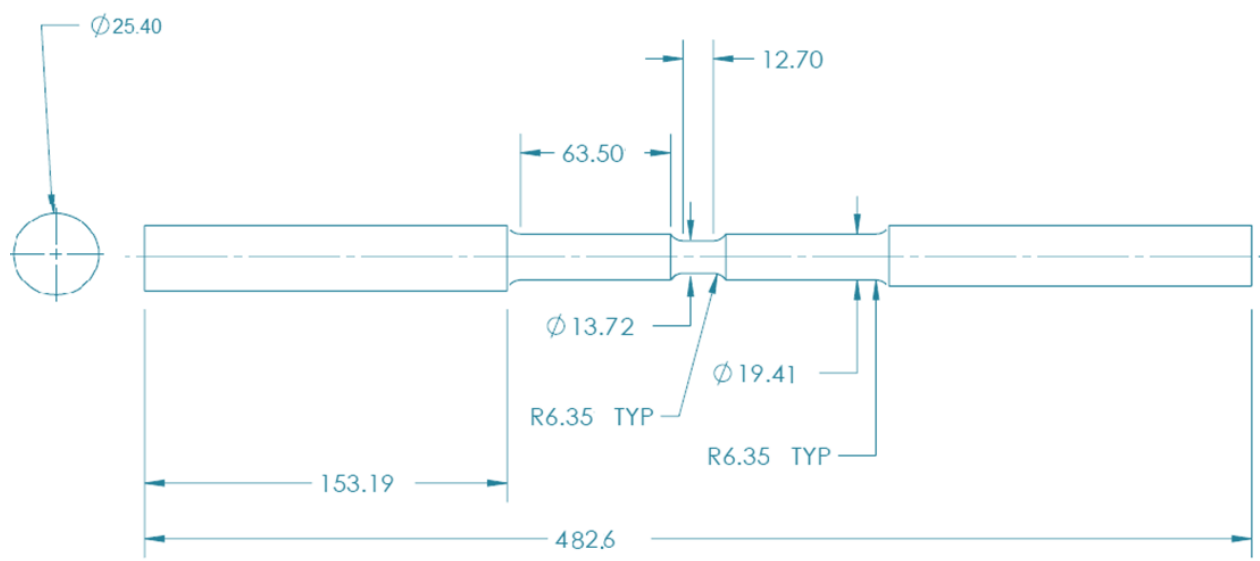

Fig. 14. Type 1 SMT solid bar specimen geometry for SS316H. Units are in mm.

Two SMT creep-fatigue tests, test \#41 with a peak tension hold time of $10 \mathrm{hr}$ and the pure fatigue test \# 43 were performed with Type 1 SMT geometry on SS316H. The results are summarized in Table 4 along with the previous test \#15 with 600 s hold time. All three tests had elastically calculated strain range of $0.3 \%$ (i.e., with the loading amplitude of $0.114 \mathrm{~mm}$ or $4.5 \mathrm{mil}$ ). The cyclic loading was fully reversed with a loading time of $3 \mathrm{~s}$. The maximum stresses measured for these three tests are compared in Fig. 15. The maximum stresses are comparable for all three tests and remained approximately constant before failure initiation. The number of cycles to failure decreased from 1250 for the pure fatigue to 410 when $600 \mathrm{~s}$ hold time was applied, and it was shown to further decrease to 180 cycles, i.e., a $85 \%$ reduction in cycle life when the hold time was increased to $10 \mathrm{hr}$. 
Table 4. Effect of tension hold times on Type 1 SMT for $\mathrm{SS316H}$ at $815^{\circ} \mathrm{C}$.

\begin{tabular}{|c|c|c|c|c|c|c|c|}
\hline Test \# & $\begin{array}{c}\text { Elastically } \\
\text { calculated } \\
\text { strain range }\end{array}$ & $\begin{array}{c}\text { Loading } \\
\text { time, } \\
\text { s }\end{array}$ & $\begin{array}{l}\text { Hold time, } \\
\text { s }\end{array}$ & $\begin{array}{l}\text { stable strain } \\
\text { range, }\end{array}$ & $\begin{array}{c}\text { Failure } \\
\text { location }\end{array}$ & $\begin{array}{l}\text { Life time, } \\
\qquad \mathrm{hr}\end{array}$ & $\begin{array}{l}\text { Cycle to } \\
\text { failure }\end{array}$ \\
\hline$\# 43$ & \multirow{3}{*}{$0.3 \%$} & \multirow{3}{*}{3} & 0 & $0.36 \%$ & \multirow{3}{*}{$\begin{array}{l}\text { Root of the } \\
\text { transition } \\
\text { radius }\end{array}$} & 4.2 & 1250 \\
\hline$\# 15$ & & & 600 & $0.62 \%$ & & 69.7 & 410 \\
\hline \#41 & & & 36,000 & $0.66 \%$ & & 1800.6 & 180 \\
\hline
\end{tabular}

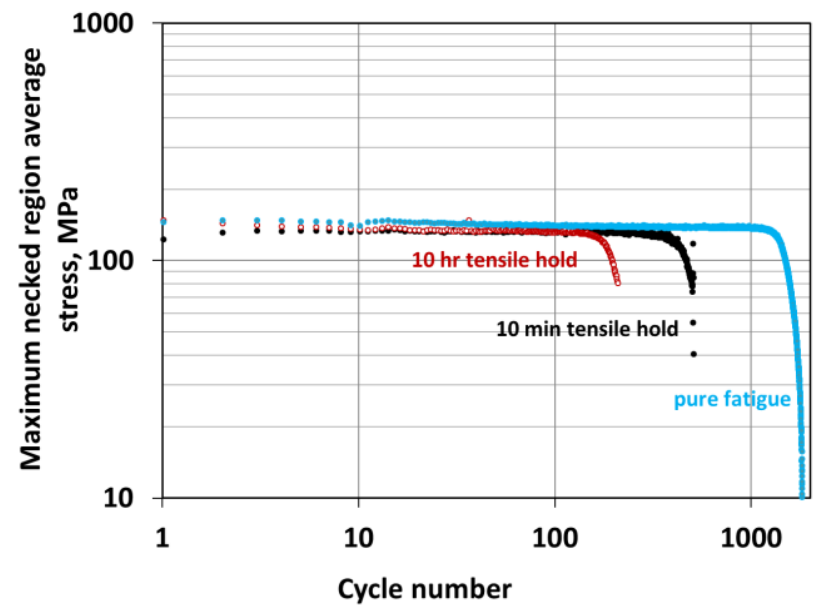

Fig. 15. Hold time effect on the maximum stresses of Type 1 SMT on SS316H with $0.3 \%$ elastically calculated strain range at $815^{\circ} \mathrm{C}$

The strain ranges measured at the uniform necked test section were $0.36 \%, 0.62 \%$ and $0.66 \%$ for the test \#43, \#15 and \#41, respectively. The significant increase in the strain range when the hold time segment was added at the peak tension is due to the elastic follow-up effect. The elastic follow-up factor for SS316H Type 1 SMT at $815^{\circ} \mathrm{C}$ was about 3.4.

Shown in Fig. 16 are plots of the measured strain range and maximum (tension) and minimum (compressive) stress as a function of cycle number, hysteresis loops and stress history of the first five cycles, ratcheting strain and a picture of the failed specimen for test \#41. Similar to what was reported for test \#15 with peak tension hold time of 600s, test \#41 also showed significant compressive ratchet strain of more than $1 \%$. The specimen failed at the root of the transition radius (indicated with a red arrow in Fig. 16f) with barreling at the necked test section. The plot of the stress history indicates that the stress in the SS316 Type 1 SMT approached to saturation with $10 \mathrm{hr}$ hold. 


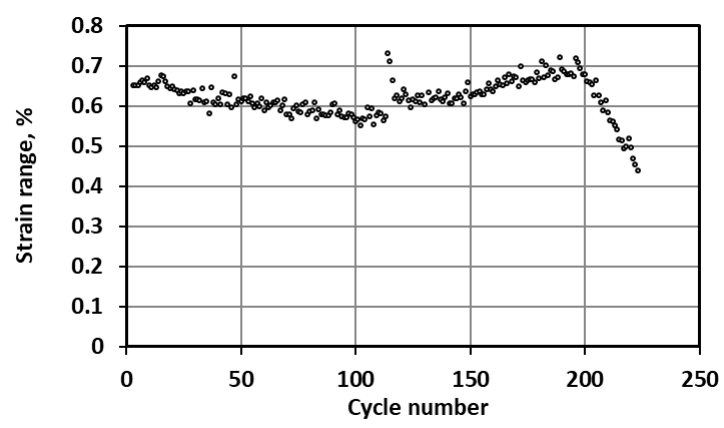

(a) Strain range

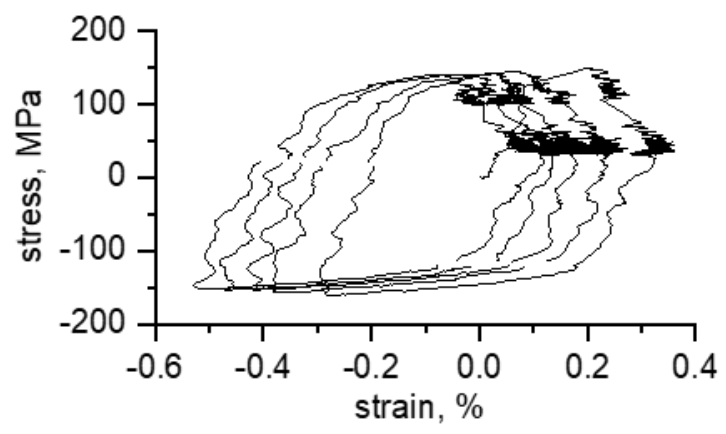

(c) Hysteresis Loop

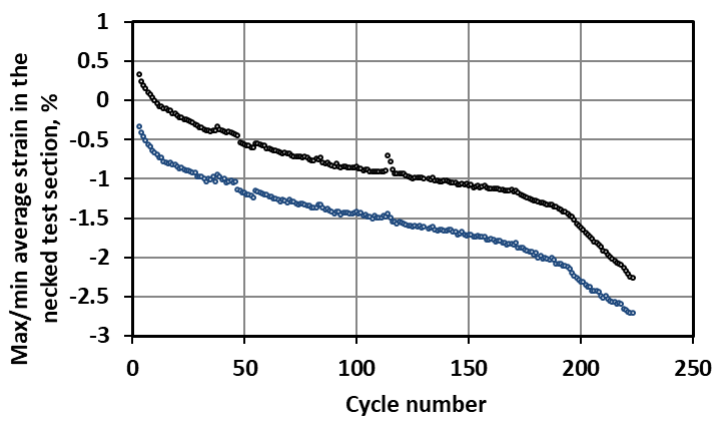

(e) Ratcheting strain

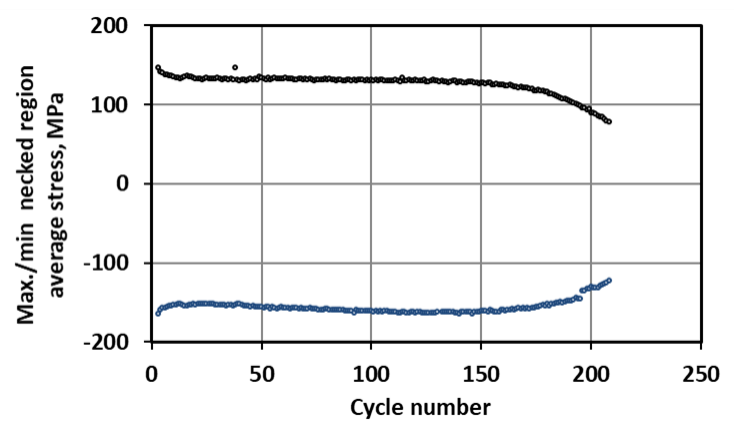

(b) Max/Min stresses

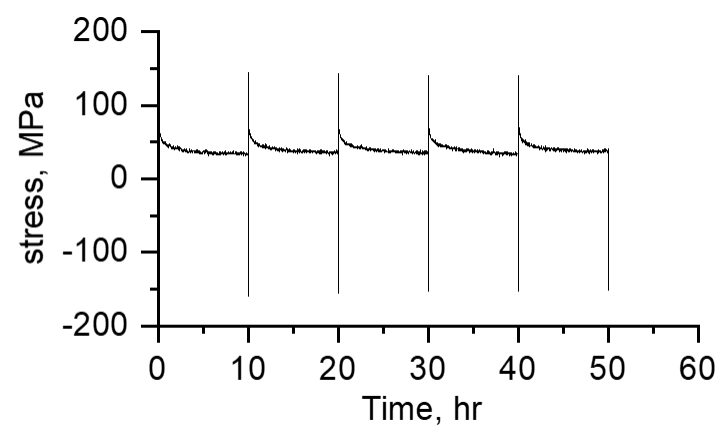

(d) Stress relaxation

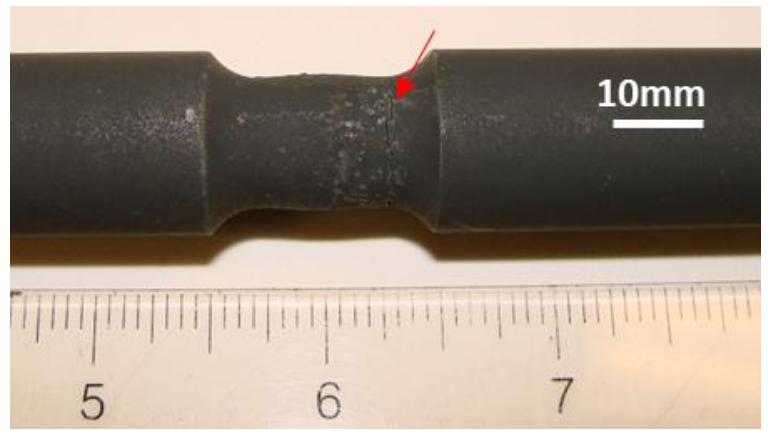

(f) Failed specimen

Fig. 16. Test results for SMT Type 1 on SS316H-test \#41.

The measured strain range, maximum and minimum stresses and strains and a picture of the failed specimen for the pure fatigue of Type 1 SMT test \#43 are shown in Fig. 17. No significant ratcheting was observed, and the specimen failed at the root of the transition radius without noticeable barreling. 


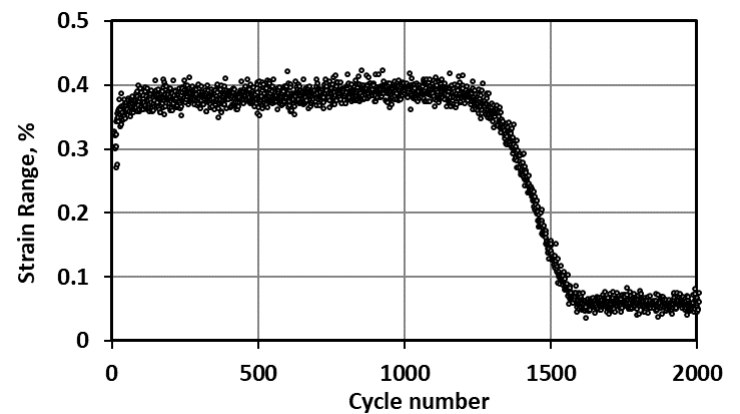

(a) Strain range

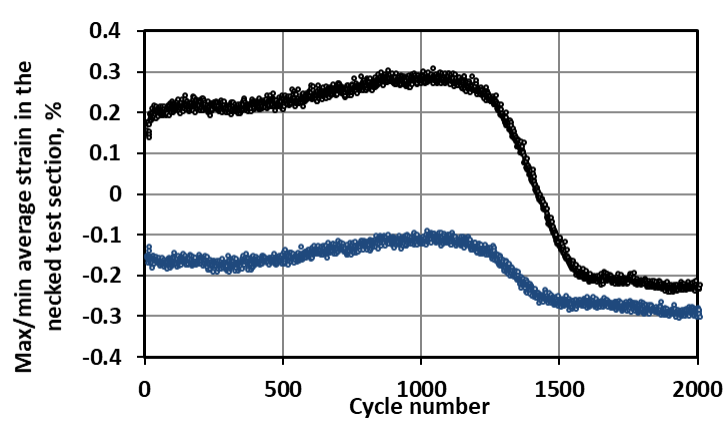

(c) Ratcheting strain

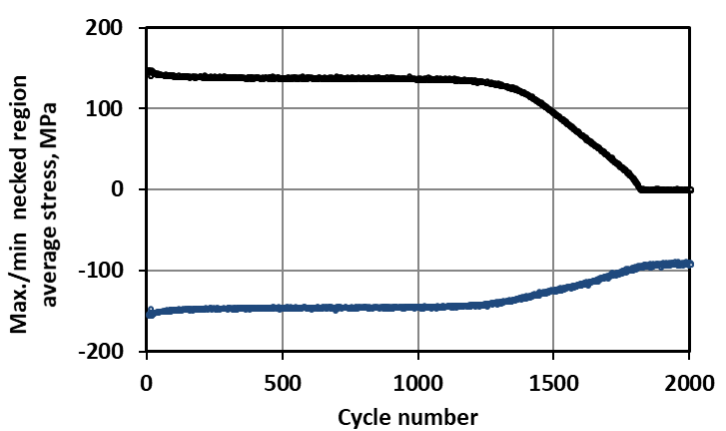

(b) Max/Min stresses

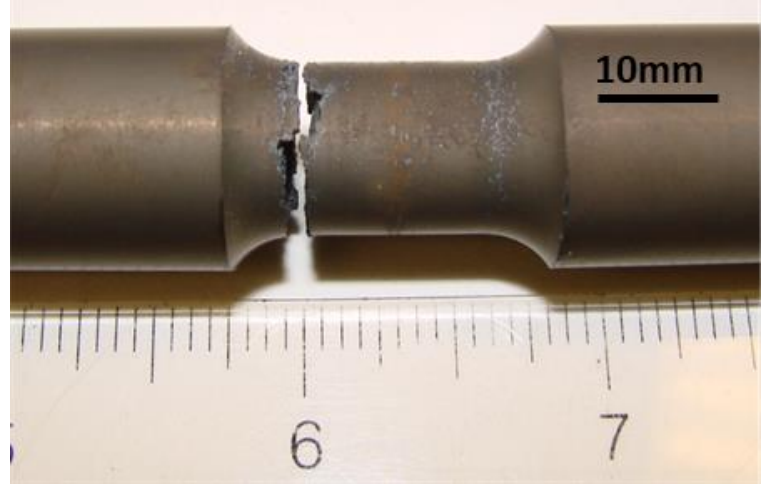

(c) Failed specimen

Fig. 17. Test results for SMT Type 1 on SS316H-test \#43.

\section{EXTENDED TESTING CAPABILITIES WITH KEY FEATURE ARTICLES FOR PRESSURE VESSELS}

Two-bar thermal rachet testing capability has been established at ORNL by Wang et al., (2013b), and test data have been generated on this system to verify the EPP strain limit code case and provide information for the development of material constitutive models. Schematics of the two-bar thermal rachet concept are shown in Fig. 18. The two bars represent the extreme fibers at the inner wall and outer wall of a pressure vessel. The test system includes two coupled servo-hydraulic machines with the control logic allow the two bars to have equal strain, yet the total applied load shared by the two bars kept constant throughout the duration of the test. The temperature profile for each bar can be defined independently to allow simulation of thermal stress being introduced to the system. The testing capability with this two-bar thermal rachet system was limited to simulate the deformation behavior of pressure vessels under constant internal pressure with a periodic across-wall secondary thermal stress. 


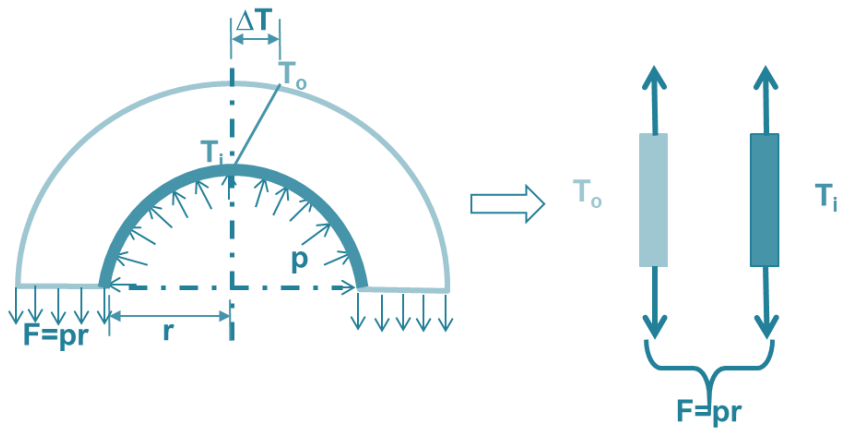

Fig. 18. Schematics of the two-bar thermal rachet concept

In FY18, the testing capability for this two-bar system were extended to more complex loading conditions. The extended testing capacities can be expressed by the equations below,

$$
\begin{aligned}
& P_{1}+P_{2}=P_{\text {total }}(t) \\
& \varepsilon_{1}-\varepsilon_{2}=\varepsilon(t)
\end{aligned}
$$

where $P$ is the load and $\varepsilon$ is the strain. The total load $P_{\text {total }}(t)$ and the difference of the strains between the two bars, $\varepsilon(t)$ can be defined as a waveform.

The cyclic total load $P_{\text {total }}(t)$ can simulate a pressure vessel with periodic internal pressure variation. This loading capability was realized by impose a command signal from LabVIEW software to automate the cyclic total load. A scope test at $650^{\circ} \mathrm{C}$ was performed on SS316H standard creep fatigue specimens. The cyclic total load history and the load responses from the two bars are shown in Fig. 19. In this case, the total load was cycled with a range of $3070 \mathrm{~N}$ and the strains of the two bars were maintained to be the same during the test.

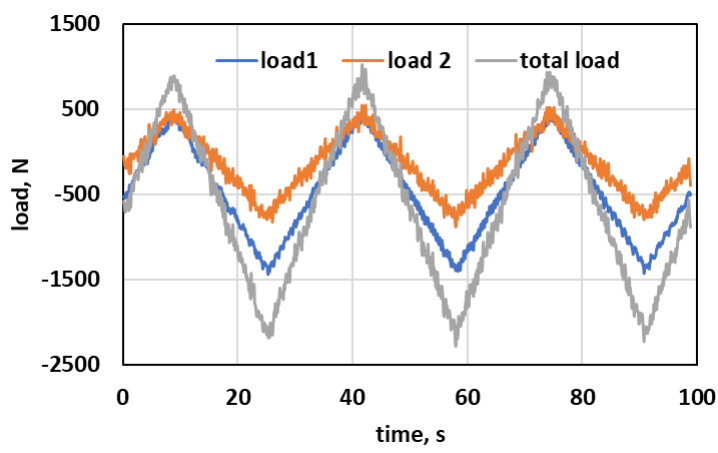

(a) load

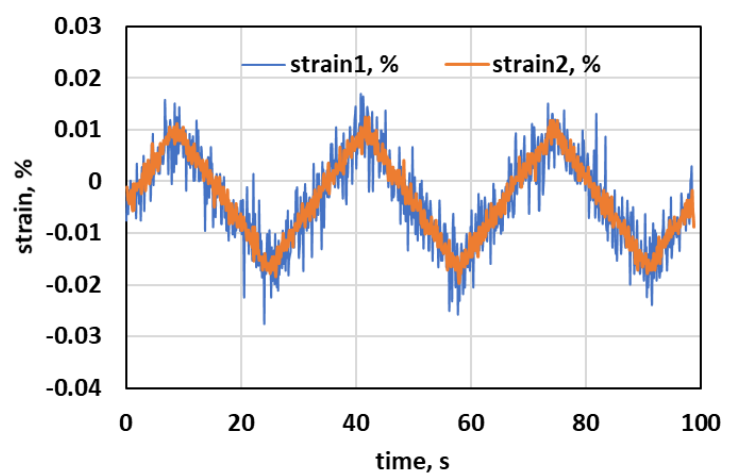

(b) strain

Fig. 19. Two-bar system simulates a pressure vessel with cyclic internal pressure 
Control of the strain differences between the two bars can simulate a pressure vessel under straincontrolled bending. This new testing capability was successfully scope tested on SS316 $\mathrm{H}$ at $815^{\circ} \mathrm{C}$. Plots of the controlled strain difference waveform $\varepsilon(t)$, the load and the strain responses of the two-bars are shown in Fig. 20. In this case, the total load was controlled to be constant and was equal to $110 \mathrm{~N}$. The two bars were found to rachet to the tensile strain direction.

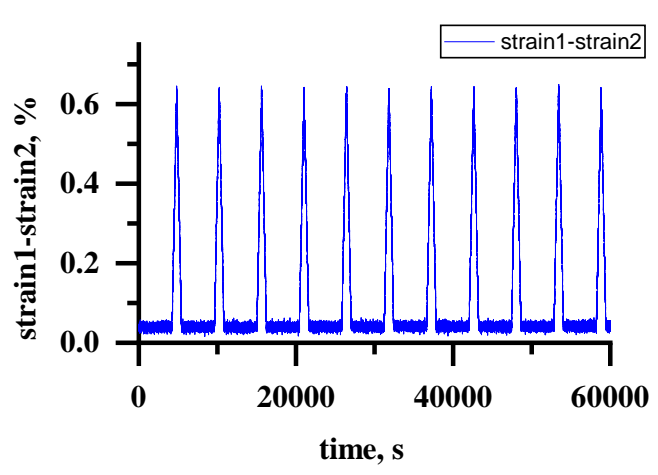

(a) controlled strain deference

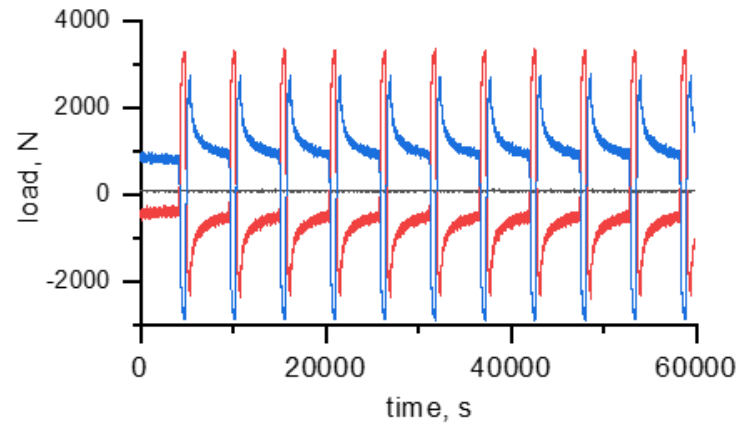

(b) load

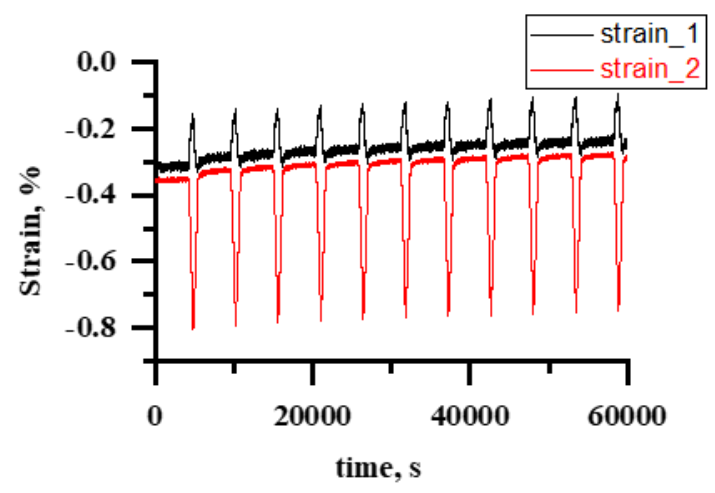

(c) strain

Fig. 20. Two-bar system simulates a pressure vessel with cyclic bending

It is worth mentioning that thermal loading, cyclic internal pressure or cyclic bending can be combined or independently carried out on the two-bar system. These extended testing capacities using the existing two-bar system can therefore simulate much more complex loading condition of a pressure vessel. 


\section{THERMOMECHANICAL TEST RESUTLS ON ALLOY 617}

Experimental data from thermomechanical fatigue are used to support the development of the material constitutive model at ANL. Thermomechanical fatigue tests were performed on Alloy 617 at a temperature range of 350 to $950{ }^{\circ} \mathrm{C}$ with heating and cooling rates of $10^{\circ} \mathrm{C} / \mathrm{min}$ using an igniter heater furnace. The specimen used has standard creep fatigue specimen geometry as shown in Fig. 4. This type of tests was designed to validate the temperature dependent parameters of the material constitutive model.

The temperature profile was controlled by a LabVIEW program. Prior to the thermomechanical fatigue test, the specimen was thermally cycled at zero load to collect thermal expansion measurement data. Thermomechanical fatigue was conducted according to standard test method ASTM-2368-10. It was under strain control with straining cycles that are 180 degrees out-of-phase with the thermal cycles, i.e., anti-phase thermomechanical fatigue. For this experiment, the total strain was controlled to be zero and the starting temperature was $650^{\circ} \mathrm{C}$. The relationship between the strain and the temperature for this antiphase thermomechanical fatigue is schematically shown in Fig. 21.

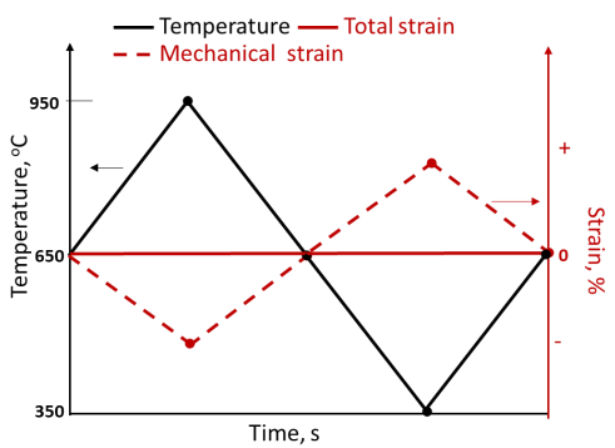

Fig. 21. Schematics of the anti-phase thermomechanical fatigue for one cycle

The average thermal expansion coefficient was determined to be $16.5 \mathrm{E}-6 \mathrm{~mm} / \mathrm{mm} /{ }^{\circ} \mathrm{C}$ using a linear fit of the free expansion curves. The average thermal expansion coefficient is consistent with previous tests on this material. The mechanical strain is calculated by subtracting the thermal expansion from the total strain. The strain range for this test was $0.99 \%$. The strain rate was determined by the heating and cooling rates, and it was $2.75 \mathrm{E}-6 \mathrm{~s}^{-1}$. The thermal cycle profile, mechanical strain history, the maximum and minimum stresses and the stress ranges are plotted in Fig. 22. The maximum/minimum stresses and stress ranges increased with applied cycles. Representative hysteresis loops and the stress vs. temperature curves are presented in Fig. 23. The material showed serrated yielding at temperature range of $450{ }^{\circ} \mathrm{C}$ to $750{ }^{\circ} \mathrm{C}$ during the thermomechanical testing. The serrated yielding between $700{ }^{\circ} \mathrm{C}$ to $800{ }^{\circ} \mathrm{C}$ during heating up process was only present for the first cycle and disappeared starting from the second cycle.

The specimen failed with ductile necking inside the gage section and the failure cycle was 231. A picture of the failed specimen is shown in Fig. 24. 


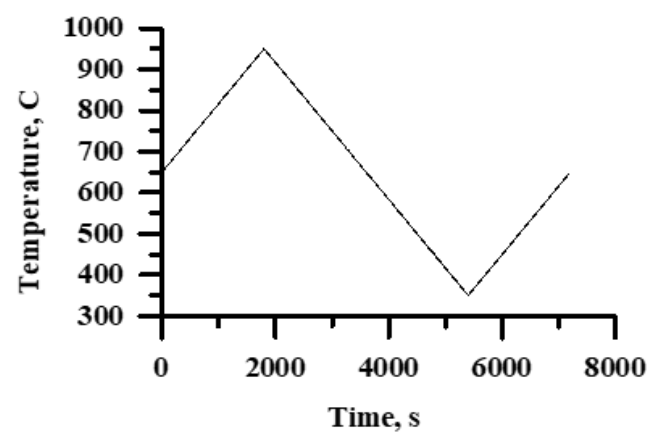

(a) Thermal cycle

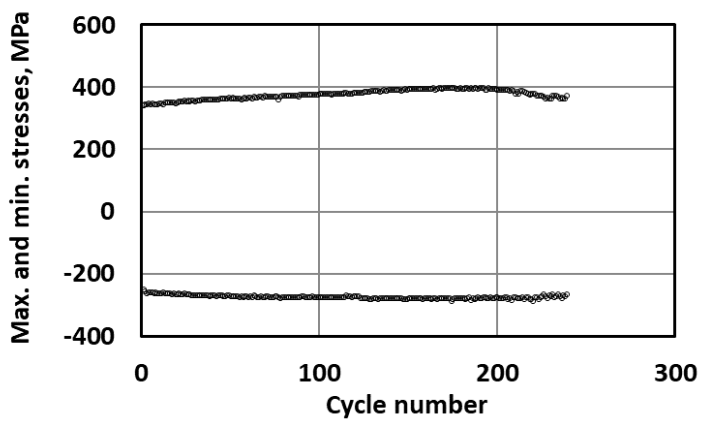

(c) Maximum and minimum stresses

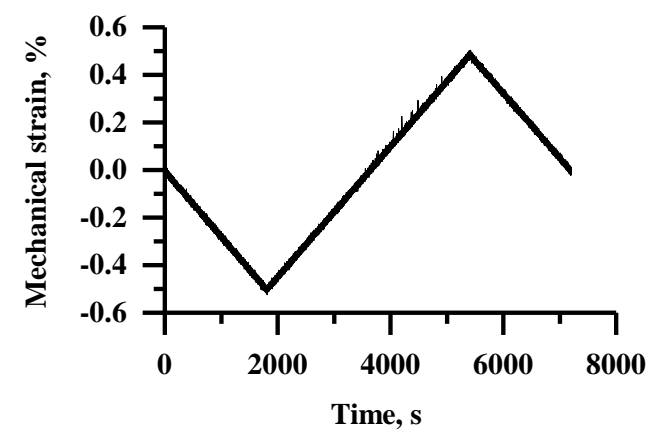

(b) Mechanical strain

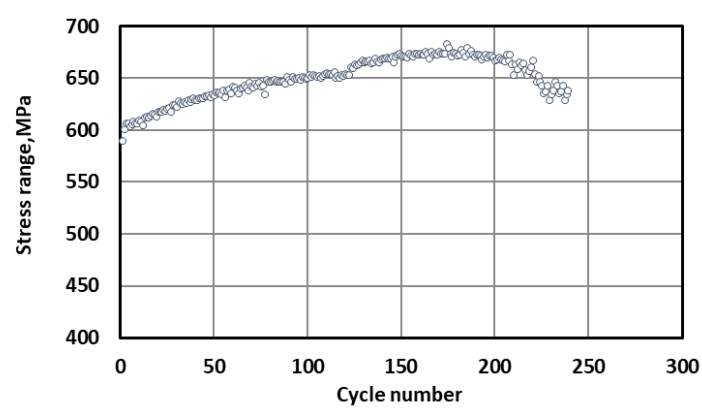

(d) Stress range

Fig. 22. Thermo-mechanical fatigue on Alloy 617 at temperature range of 350 to $950{ }^{\circ} \mathrm{C}$.

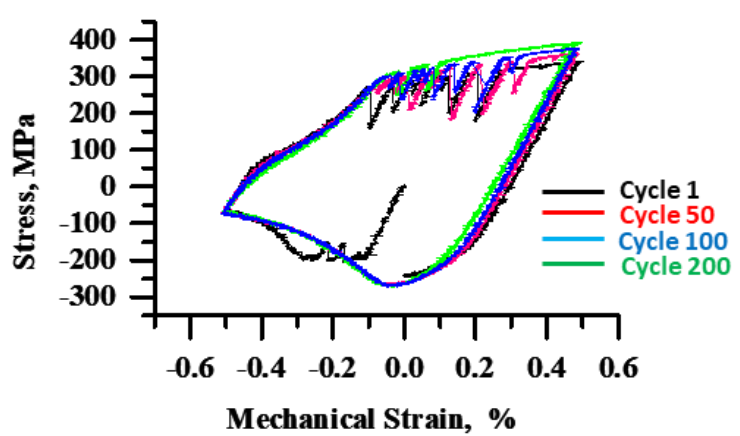

(a) Hysteresis loops

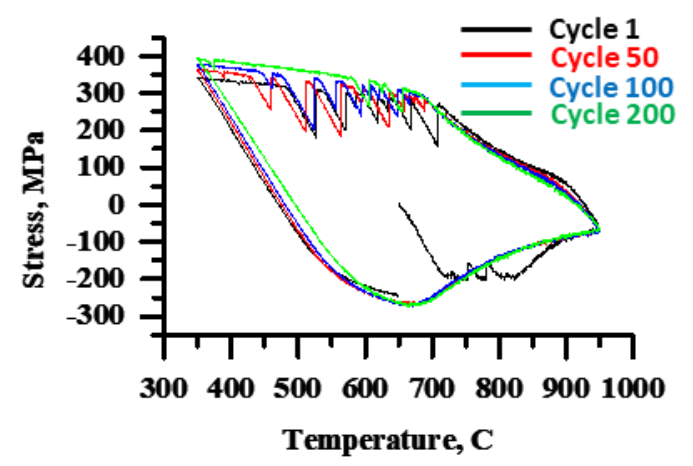

(b) stress vs. temperature

Fig. 23. Representative hysteresis loops and stress vs. temperature curves for the thermomechanical fatigue on Alloy 617 at temperature range of 350 to $950{ }^{\circ} \mathrm{C}$.

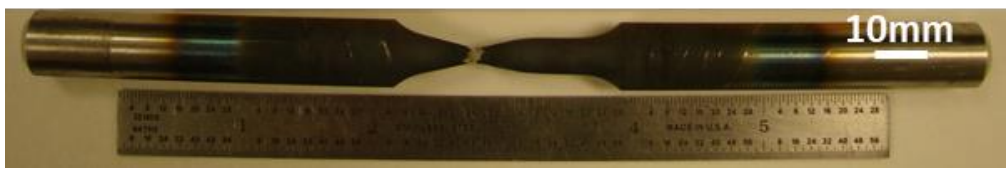

Fig. 24 Picture of the failed Alloy 617 specimen after thermomechanical fatigue 


\section{SUMMARY}

The experimental results in support of the development of the integrated EPP combined SMT creepfatigue damage evaluation approach are summarized in this report. The goal of the proposed approach is to combine the advantage of the EPP strain limits methodology that avoids stress classification with the advantage of the SMT method for evaluating creep-fatigue damage without deconstructing the cyclic history into separate fatigue and creep damage evaluations.

Two innovative SMT based experimental methods, i.e., two-bar SMT and single smooth bar SMT, are fully developed and successfully scope tested. The new test methods allow the use of standard creep fatigue specimens to evaluate effect of the elastic follow-up for creep fatigue evaluation. The single smooth bar SMT method shows the potential of further development into a standard testing method for the application of SMT based creep fatigue evaluation.

Experiments were performed on SS316 Type 1 SMT key feature articles with long tension hold times of $10 \mathrm{hr}$ at $815^{\circ} \mathrm{C}$. The test results were compared with the pure fatigue SMT experiment and SMT with a hold time of $600 \mathrm{~s}$. The number of cycles to failure was shown to decease by $85 \%$ when the hold time was increased to $10 \mathrm{hr}$. These results support the development of SMT based design curve with extrapolation to much longer hold times representative of operation conditions.

The role of the primary load on SMT creep fatigue life for Alloy 617was evaluated at a low strain range of $0.12 \%$ using pressurized SMT. The results confirmed that the SMT creep fatigue life for Alloy 617 is independent of the primary load when it is below the allowable value.

Key feature tests using two-bar thermal ratcheting system were extended to more complex loading conditions including thermal load, cyclic internal pressure or cyclic bending.

In addition, thermomechanical tests at temperature range of 350 to $950{ }^{\circ} \mathrm{C}$ were performed on Alloy 617 . The data were used to support the material constitutive model development for Alloy 617. 


\section{REFERENCES}

ASME B\&PV Code Case N-861 "Satisfaction of Strain Limits for Division 5 Class A Components at Elevated Temperature Service Using Elastic-Perfectly Plastic Analysis”.

ASME B\&PV Code Case N-862 "Calculation of Creep-Fatigue for Division 5 Class A Components at Elevated Temperature Service Using Elastic-Perfectly Plastic Analysis Section III, Division 5”.

ASMT E2714, "Standard Test Method for Creep-Fatigue Testing”, ASTM International, West Conshohocken, PA.

ASTM-2368, "Standard Practice for Strain Controlled Thermomechanical Fatigue Testing”, West Conshohocken, PA.

Carroll, L. J., Cabet, C., R. Madland and Wright, R. N., (2011). "Creep and Environmental Effects on the High Temperature Creep-fatigue Behavior of Alloy 617," Journal of ASTM International, Vol. 8, No. 6, pp. 1-13, https://doi.org/10.1520/JAI103797.

M. C. Messner, T. L. Sham, Y. Wang and R. I. Jetter (2018), "Evaluation of methods to determine strain ranges for use in SMT design curves", ANL-ART-138, Argonne National Laboratory.

Wang, Y., Jetter, R. I., Krishnan, K., and Sham, T.-L, (2013a) "Progress Report on Creep-Fatigue Design Method Development Based on SMT Approach for Alloy 617”, ORNL/TM-2013/349, Oak Ridge National Laboratory, Oak Ridge, TN.

Wang, Y., Sham, T.-L, and Jetter, R. I., (2013b), "Progress report on the development of test procedure for the two-bar thermal ratcheting experiment for Alloy 617", ORNL/TM-2013/318, Oak Ridge National Laboratory, Oak Ridge, TN.

Wang, Y., Jetter, R. I. and Sham, T.-L, (2014), “Application of Combined Sustained and Cyclic Loading Test Results to Alloy 617 Elevated Temperature Design Criteria”, ORNL/TM-2014/294, Oak Ridge National Laboratory, Oak Ridge, TN.

Wang, Y., Jetter, R. I., Baird, S. T., Pu, C. and Sham, T.-L., (2015), "Report on FY15 Two-Bar Thermal Ratcheting Test Results”, ORNL/TM-2015/284, Oak Ridge National Laboratory, Oak Ridge, TN.

Wang, Y., Jetter, R. I., and Sham, T.-L., (2016a), "FY16 Progress Report on Test Results In Support Of Integrated EPP and SMT Design Methods Development” ORNL/TM-2016/330, Oak Ridge National Laboratory, Oak Ridge, TN.

Wang, Y., Jetter, R. I., and Sham, T.-L., (2016b), "Preliminary Test Results in Support of Integrated EPP and SMT Design Methods Development", ORNL/TM-2016/76, Oak Ridge National Laboratory, Oak Ridge, TN.

Y. Wang, R. I. Jetter and T.-L. Sham, (2017a), "Report on FY17 Testing in Support of Integrated EPPSMT Design Methods Development”, ORNL/TM-2017/351, Oak Ridge National Laboratory, Oak Ridge, TN.

Wang, Y., Jetter, and Sham, T.-L., (2017b), "Pressurized Creep-Fatigue Testing of Alloy 617 Using Simplified Model Test Method", Proceedings of the ASME 2017 Pressure Vessels and Piping Conference, PVP2017-65457 
Wang, Y., Jetter, R. I., Messner, M., Mohanty, S., and Sham, T.-L., (2017c), “Combined Load and Displacement Controlled Testing to Support Development of Simplified Component Design Rules for Elevated Temperature Service", Proceedings of the ASME 2017 Pressure Vessels and Piping Conference, PVP2017-65455

Wang, Y., Messner and Sham, T.-L., (2018), "Report on the FY18 Uniaxial Material Model Testing and Key Feature Test Articles Testing of Grade 91”, ORNL/TM-2017/388, Oak Ridge National Laboratory, Oak Ridge, TN. 


\section{ELECTRONIC DISTRIBUTION}

\begin{tabular}{ll} 
Name & Affiliation \\
Lesica, S. & DOE-NE \\
Gougar, H. & INL \\
Grandy, C. & ANL \\
Hill, R.N. & ANL \\
Jetter, R.I. & R.I. Jetter Consulting \\
Lara-Curzio, E. & ORNL \\
Li, D. & DOE-NE \\
Lin, L. & ORNL \\
McMurtrey, M. & INL \\
Messner, M.C. & ANL \\
Natesan, K. & ANL \\
Qualls, L. & ORNL \\
Robinson, B. & DOE-NE \\
Sham, T.-L. & ANL \\
Wang, H. & ORNL \\
Wang, Y. & ORNL \\
Wright, R.N. & INL \\
Yankeelov, J. & DOE-ID \\
\hline
\end{tabular}

\begin{tabular}{|c|}
\hline Email \\
\hline sue.lesica@nuclear.energy.gov \\
\hline Hans.Gougar@inl.gov \\
\hline cgrandy@anl.gov \\
\hline bobhill@anl.gov \\
\hline bjetter@sbcglobal.net \\
\hline laracurzioe@ornl.gov \\
\hline Diana.Li@nuclear.energy.gov \\
\hline linl@ornl.gov \\
\hline michael.mcmurtrey@inl.gov \\
\hline messner@anl.gov \\
\hline natesan@anl.gov \\
\hline quallsal@ornl.gov \\
\hline Brian.Robinson@Nuclear.Energy.gov \\
\hline ssham@anl.gov \\
\hline wangh@ornl.gov \\
\hline wangy3@ornl.gov \\
\hline richard.wright@inl.gov \\
\hline yankeeja@id.doe.gov \\
\hline
\end{tabular}

